\title{
High Power Picosecond Laser Surface Micro-texturing of H13 Tool Steel and Pattern Replication onto ABS Plastics via Injection Moulding
}

\author{
Omonigho B. Otanocha ${ }^{1}$ (D) $\cdot \operatorname{Lin} \mathrm{Li}^{1} \cdot \operatorname{Shan} \mathrm{Zhong}^{1} \cdot$ \\ Zhu Liu ${ }^{2}$
}

Accepted: 4 December 2015 / Published online: 4 January 2016

(C) The Author(s) 2016. This article is published with open access at Springerlink.com

\begin{abstract}
H13 tool steels are often used as dies and moulds for injection moulding of plastic components. Certain injection moulded components require micro-patterns on their surfaces in order to modify the physical properties of the components or for better mould release to reduce mould contamination. With these applications it is necessary to study micro-patterning to moulds and to ensure effective pattern transfer and replication onto the plastic component during moulding. In this paper, we report an investigation into high average powered $(100 \mathrm{~W})$ picosecond laser interactions with $\mathrm{H} 13$ tool steel during surface micro-patterning (texturing) and the subsequent pattern replication on ABS plastic material through injection moulding. Design of experiments and statistical modelling were used to understand the influences of laser pulse repetition rate, laser fluence, scanning velocity, and number of scans on the depth of cut, kerf width and heat affected zones (HAZ) size. The characteristics of the surface patterns are analysed. The process parameter interactions and significance of process parameters on the processing quality and efficiency are characterised. An optimum operating window is recommended. The transferred geometry is compared with the patterns generated on the dies. A discussion is made to explain the characteristics of laser texturing and pattern replication on plastics.
\end{abstract}

Keywords Laser Picosecond - Ablation · Texturing $\cdot \mathrm{H} 13$ tool steel $\cdot$ Heat affected zone (HAZ) · Design of experiments · Replication · Injection moulding · Pattern transfer

Omonigho B. Otanocha

Omonigho.Otanocha@postgrad.manchester.ac.uk

1 School of Mechanical, Aerospace and Civil Engineering, The University of Manchester, Manchester M13 9PL, UK

2 School of Materials, The University of Manchester, Manchester M13 9PL, UK 


\section{Introduction}

Surface textures of an engineering component can affect their interactions with the surrounding fluid media, for example, the aerodynamic characteristics of airplanes, ships, wind turbines, mechanical separators, and sports balls can be affected by surface texture as well as their geometry. The use of micro/nano patterns is one of the methods of influencing surface texture.

There are challenges in the fabrication of user-defined micro/nano - patterns on solid surfaces in a controlled, repeatable and economic manner with minimal post-processing and defects. Current micro- and nano - surface modification techniques include chemical etching [1, 2], mechanical abrasion (sanding/sand blasting), diamond machining, electron beam machining, plasma machining, focused ion beam machining and laser surface patterning. Due to specific periodic micro-patterns required for surface functions, effective production of large area micro-patterns on flat and curved surfaces is challenging. Laser micro/nano-processing technology could be a viable tool in achieving design objectives with high productivity, while ensuring best product quality and value added engineering. The extent to which nano- and micro-meter scale structures could be transferred from a laser structured metal mould to polymer depends on large number of factors which includes: surface finish of the mould, aspect ratio of the features, moulding pressure and temperature, viscosity and other intrinsic surface properties of the plastic [3, 4].

The relationships between processing parameters during laser processing greatly affect the quality of the material outcome. These parameters include the laser pulse length, wavelength, power, pulse repetition rate, laser scanning or traversing speed, and laser beam spot size as well as processing environment and material properties $[5,6]$. An equally important factor in laser interaction with materials is the laser beam intensity (power density) or fluence (energy density).

Pulsed laser ablation and material removal in metallic materials is mainly due to the processes of melt ejection and vaporisation. At a low laser flux, the target material absorbs laser energy and evaporates or sublimates. At a high laser flux, the material is converted to the plasma state and melt ejection takes place. The rate of energy delivery from an ultra-short pulsed (in the picosecond and femtosecond regime) laser beam into the near-surface regions of a solid involves extremely short periodic electronic excitation and de-excitation. Thus, the entire input energy is inadequate to cause considerable damage to the bulk material [6-9].

There has been a demonstrable increase in the acceptance of ultra-short pulsed lasers for micro-machining and they can be used to process a wider range of materials than conventional methods including metals, ceramics, composites, semiconductors and polymers $[10,11]$. The machining process during laser interaction with the material is usually characterised by the ablation rate and expressed as depth per pulse $[12,13]$.

Despite various studies on ultra-short laser interaction with materials, there has been little study on the parameter interactions during high power picosecond laser patterning of H13 tool steels and the characteristics of their pattern transfer to plastic materials.

Some researchers have reported a direct correlation between the surface finish of the mould and dynamics of the melt flow during injection moulding [4, 14]. For plastic injection moulding, the pressure at which molten polymer is injected and its corresponding temperature $[15,16]$ control the moulding process. With micro injection 
moulding [17], related structures have been reported with widths and lengths of $0.1-$ $100 \mu \mathrm{m}$ and $0.01-4$ aspect ratios [18, 19].

This paper reports an investigation into multi-parameter interactions in high power picosecond laser patterning of H13 tool steel sheets and the characteristics of micropattern transfer to ABS (acrylonitrile-butadiene-styrene) plastic materials from a patterned tool through injection moulding.

\section{Experimental materials and procedures}

\section{H13 tool steel}

H13 tool steel is an industrial grade alloy steel containing carbon, manganese, silicon, chromium, phosphorus, molybdenum, and vanadium, as basic alloying elements. These alloying elements confer mechanical and thermal qualities (such as hardness, wear and corrosion resistance) on this steel grade needed for better functionality and dimensional integrity in output delivery. The composition of the material used in this investigation is shown in Table 1.

H13 tool steel bulk materials were received as sheets of $420 \mathrm{~mm} \times 185 \mathrm{~mm} \times 24.2 \mathrm{~mm}$ thick from a commercial supplier, with composition as shown in Table 1 . These blocks were cut into specimens of $20 \mathrm{~mm} \times 25 \mathrm{~mm} 2 \mathrm{~mm}$ thick using a wire EDM (Electro-Discharge Machine). The specimens were then shot blasted with fine grits, to produce even surfaces $(\mathrm{Ra}=1.3 \mu \mathrm{m} ; \mathrm{Rp}=6.6 \mu \mathrm{m} ; \mathrm{Rq}=1.7 \mu \mathrm{m}$; and $\mathrm{Rz}=14.7 \mu \mathrm{m})$ devoid of surface impurities, and thereafter cleaned with compressed air to remove dust. These were used as work pieces for the experiments. Surface characterisation was performed on H13 specimens after shotblasting with a WYKO optical white light surface profiler as shown in the Fig. 1.

\section{Acrylonitrile butadiene styrene (ABS)}

ABS (acrylonitrile-butadiene-styrene) is formed by the simultaneous chemical reaction of acrylonitrile, butadiene, and styrene monomers. The resultant thermoplastic is endowed with desirable characteristics to achieve impact resistance and toughness and comparable ease of processing [21]. Other properties that make ABS good for certain parts are: dimensional stability, stiffness, colourability, surface finish and cost. These properties make ABS a favourable choice in the manufacture of varieties of house hold electro-mechanical appliances, computer casing, car door panels, and refrigerator door linings, amongst others. ABS has an estimated glass transition temperature of $105{ }^{\circ} \mathrm{C}$, with no exact melting point due to its amorphous nature. In this project, ABS is melted and moulded over laser patterned $\mathrm{H} 13$ tool steel core inserts through an injection moulding process. The resin used for the injection moulding

Table 1 H13 Tool steel data sheet as supplied from - metal supplies Ltd [20]

Chemical composition (\%)

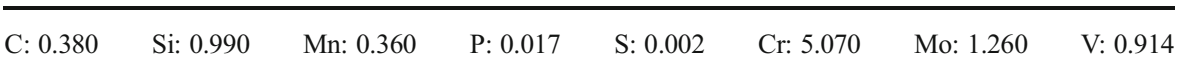



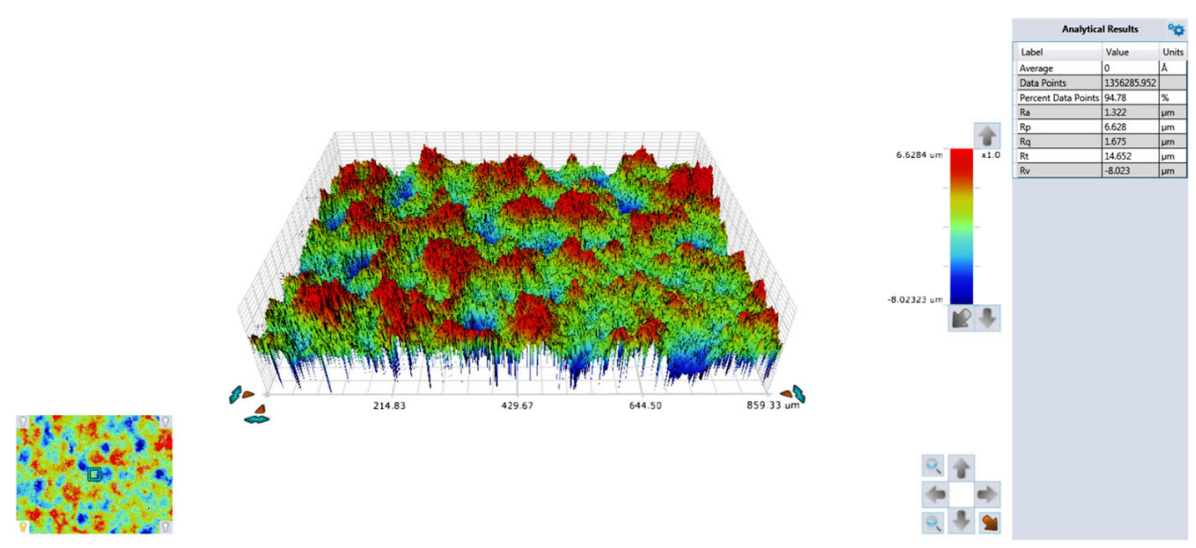

Fig. 1 H13 specimen roughness profile after shot-blasting

process was black coloured ABS plastic supplied as cylindrical granules of $2.2 \mathrm{~mm}$ diameter with an average length of $3.0 \mathrm{~mm}$. These granules were moulded into $20 \mathrm{~mm}$ $\times 25 \mathrm{~mm} 2 \mathrm{~mm}$ thick sheets, using flat specimens of H13 as secondary mould (Table 2).

Surface roughness characteristics for the moulded $2 \mathrm{~mm}$ thick flat sheets of ABS are as shown in the Fig. 2. A WYKO optical interferometer was used, with measurement values as: $\mathrm{Ra}=0.9 \mu \mathrm{m}, \mathrm{Rp}=5.6 \mu \mathrm{m}, \mathrm{Rq}=1.2 \mu \mathrm{m}$, and $\mathrm{Rz}=19.2 \mu \mathrm{m}$.

\section{Experimental procedure}

An Edgewave picosecond laser machine (Model: QX; SN 0416) was used for microfabrication processes in this research work. The laser is a diode pumped system

Table 2 Technical data sheet for ABS 35 (01a) as supplied by PERRITE, Vita Thermoplastic Compounds Ltd [21]

\begin{tabular}{lll}
\hline Physical properties & Test method & SI units \\
\hline Density & ISO 1183 & $1.04 \mathrm{~g} / \mathrm{cm}^{3}$ \\
Melt flow rate $\left(220{ }^{\circ} \mathrm{C} / 10 \mathrm{Kg}\right)$ & ISO 1133 & $27 \mathrm{~g} / 10 \mathrm{~min}$ \\
Mechanical properties & Test Method & SI Units \\
Elongation at break & ISO 527 & $20 \%$ \\
Flexural modulus & ISO 178 & $2450 \mathrm{Mpa}$ \\
Flexural yield strength & ISO 178 & $65 \mathrm{Mpa}$ \\
Tensile modulus & ISO 527 & $2400 \mathrm{Mpa}$ \\
Tensile yield strength & ISO 527 & $45 \mathrm{Mpa}$ \\
Impact properties & Test Method & $\mathrm{SI} \mathrm{Units}$ \\
Izod impact (notched) @ $23{ }^{\circ} \mathrm{C}$ & ASTM D 256 & $18 \mathrm{KJ} / \mathrm{m}^{2}$ \\
Thermal properties & Test Method & $\mathrm{SI} \mathrm{Units}$ \\
Heat distortion temperature $-@ 0.45 \mathrm{Mpa}$ & ISO 75-2 & $94{ }^{\circ} \mathrm{C}$ \\
Heat distortion temperature $-@ 1.8 \mathrm{Mpa}$ & ISO $75-2$ & $88{ }^{\circ} \mathrm{C}$ \\
Vicat softening point $\left(5 \mathrm{Kg} / 50{ }^{\circ} \mathrm{C} / \mathrm{Hr}\right)$ & ISO 306 B & $97 \mathrm{C}$ \\
\hline
\end{tabular}



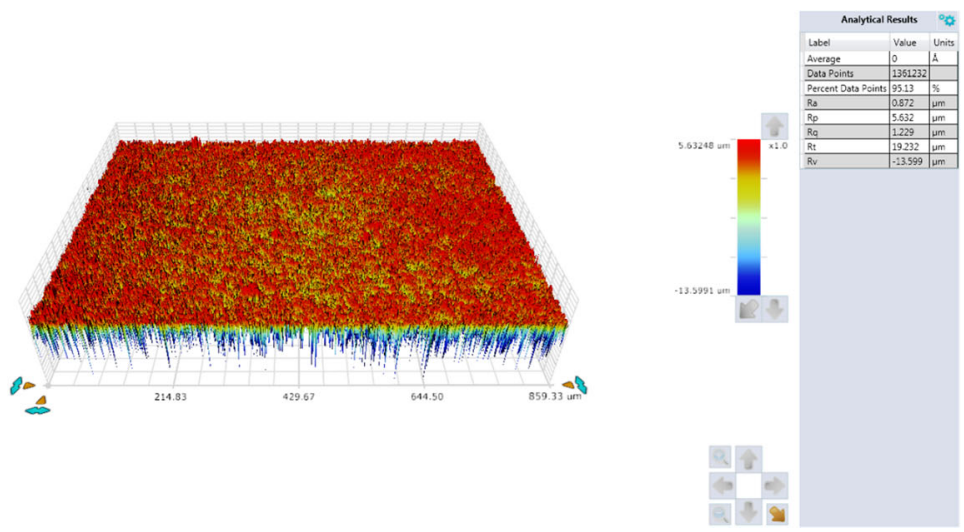

Fig. 2 ABS specimen roughness profile after injection moulding on shot-blasted H13 tool

(oscillator: $\mathrm{Nd}: \mathrm{YVO}_{3}$ ) with an optical emission wavelength of $1064 \mathrm{~nm}$ (infrared, invisible) at a pulse length of $10 \mathrm{ps}$ operating at a repetition rate of $102 \mathrm{kHz}-$ 19.2 MHz. The laser was operated with an average output power up to $100 \mathrm{~W}$, with pulse energy up to $1 \mathrm{~mJ}$ and maximum peak power at $100 \mathrm{MW}$. The beam quality factor $M^{2}=1.2$ and pulse energy stability $<4 \% \mathrm{rms}$ variation. Laser beam was diverted by several mirrors into a galvo scanning mirror then focused by an F-theta lens. The incorporated galvo (Scanlab Curryscan 20) scanning system had scan rates up to $10 \mathrm{~m} /$ s. This was located on a PRO 165 Aerotech vertical Z-axis: $400 \mathrm{~mm}$ traverse range, $0.5 \mu \mathrm{m}$ resolution, $1 \mathrm{um}$ repeatability, $2 \mu \mathrm{m}$ accuracy, $150 \mathrm{~mm} / \mathrm{s}$ maximum velocity. The specimen stage was an Aerotech high dynamic XY- linear motor table: $400 \mathrm{~mm} \times$ $400 \mathrm{~mm}$ traverse, $20 \mathrm{~nm}$ resolution, $2 \mu \mathrm{m}$ accuracy, maximum velocity $500 \mathrm{~mm} / \mathrm{s}$, maximum acceleration $0.5 \mathrm{~g}$, maximum load $75 \mathrm{~kg}$. Control unit includes a computer and display ( $\mathrm{G} \& \mathrm{M}$ codes) and Windows based software to control the laser, the translation tables and the scanner.

The H13 specimens were processed in air, without use of assist gas, with the laser (focal length of $330 \mathrm{~mm}$ ) focused on the target surface.

The experimental set up for the picosecond laser micro - patterning of H13 specimens is shown in Fig. 3. Micro-patterns were generated from CAD drawings of straight lines (for grooves) and circles (for dimple). These patterns were machined in arrays and laser scanning repetitions made it possible to increase the etching depths.

After laser micro-machining, the H13 samples were cleaned with ethanol and compressed air with a pressure set at 5.5 Bars applied to remove any surface contamination and ablated debris, respectively. Some laser machined specimens were cut along their lengths and mounted in transparent $30 \mathrm{~mm}$ thermoplastic moulds, then ground, and polished with $1 \mu \mathrm{m}$ diamond paste. Thereafter, the mounted specimens were etched with $2 \%$ nital for 10 seconds, before micro-structural inspection to evaluate the micromachining quality with a Hitachi scanning electron microscope (SEM) and KEYENCE 3D Digital optical microscope.

The micro-patterned H13 material was mounted as an insert (secondary tool) on an injection moulding machine. Grooves were replicated as riblets, while dimples became bumps on the surfaces of the ABS plastic, after the moulding process. 


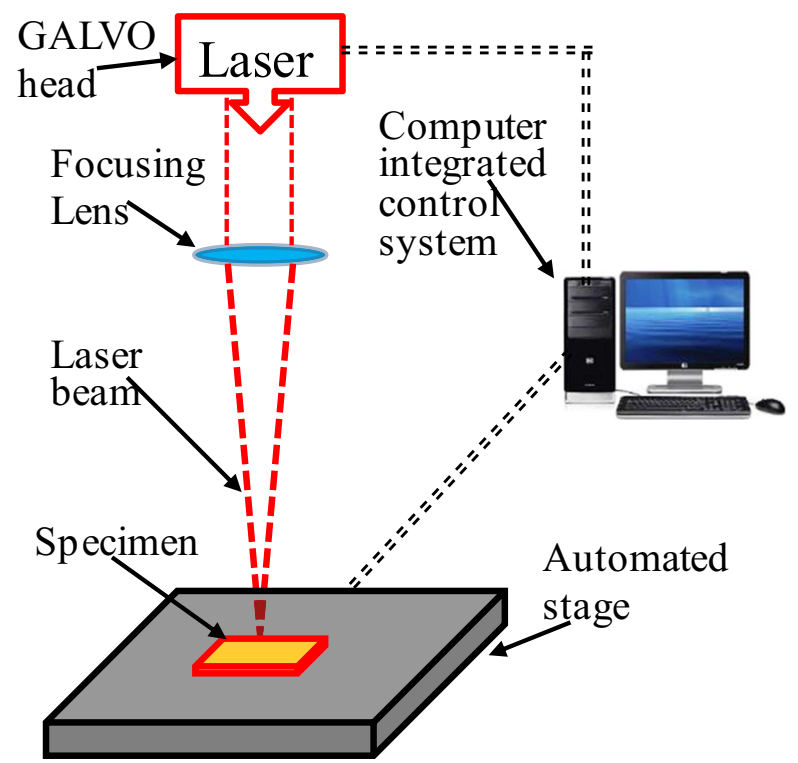

Fig. 3 Schematic for picosecond (PS) laser micro-patterning of H13tool steel flat specimen, with five axes motion capabilities

The equipment for injection moulding comprised of a screw driven system with three separate heating regions, and an aligned section for the moulding tool, where it was clamped before injection moulding took place. Plastic pellets were manually fed into the injection moulding machine (EasyMold 77/30) through the hopper after drying for four hours at $80{ }^{\circ} \mathrm{C}$ in an oven. The resin was sequentially transported by reciprocating screw attached to the motorised unit, through the feed zone, then on to the melt zone and finally the metering zone where the melted material was injected at 80 Bars into the mould. The mould was clamped to withstand the pressure applied. A band of controlled heaters provided external heating $\left(220-240^{\circ} \mathrm{C}\right)$. After the moulding processes, the plunger was retracted and the clamping device disengaged to access the tool, before the moulded sample was extracted.

\section{Design of experiments and statistical modelling procedure}

Response surface method (RSM) is widely accepted as a statistical modelling tool designed to minimise time, production costs and general complexities involved with other related analytical techniques. RSM as a concurrent engineering tool promotes practical model improvements on interactions between multiple input variables denoted by $x_{i}$ and various outcomes of interest (y), for optimisation of the process [22-28].

RSM as an empirical model could be used in the improvement of a satisfactory and functional interactive relationship (based on the fundamental engineering, chemical, or physical theories) between a response variable of interest, $\mathrm{y}$, and input/predictor variables represented by $x_{i}, x_{j}$, in the universal form of a polynomial [23]:

$$
y=\varepsilon_{0}+\sum_{i=1}^{k} \beta_{i} x_{i}+\sum_{i<j} \sum_{i=1}^{k} \beta_{i j} x_{i} x_{j}+\sum_{i=1}^{k} \beta_{i i} x_{i}^{2}+\beta_{0}
$$


Where:

$\varepsilon_{0} \quad$ random experimental error in the system

$\beta \quad$ vector of $\mathrm{p}$ (number of model parameters) indefinite coefficients

$\beta_{0} \quad$ response at the centre point

$\beta_{i} \quad$ coefficient of the main linear components

$\beta_{\mathrm{ij}}$ coefficient of the two linear factor interactions, and

$\beta_{\mathrm{ii}}$ coefficient of the quadratic factor

The central composite design (CCD) is a sub-method of RSM, used to develop a second order polynomial model, which can be used to optimise the responses of interest in a process. It can fit second order polynomial with high accuracy, and represent a good accuracy for process optimisation.

For a the second order model

$$
y=\varepsilon_{0}+\beta_{1} x_{1}+\beta_{2} x_{2}+\beta_{12} x_{i} x_{2}+\beta_{11} x_{1}^{2}+\beta_{22} x_{2}^{2}++\beta_{0}
$$

Considering fitting the above quadratic model, the hypotheses of interest would be:

$$
\begin{aligned}
& \mathrm{H}_{0}: \beta_{11}=\beta_{22}=\beta_{12}=0 \\
& \mathrm{H}_{1}: \beta_{11} \neq 0 \text { and } / \text { or } \beta_{22} \neq 0 \text { and } / \text { or } \beta_{12} \neq 0
\end{aligned}
$$

The CCD method was utilised in the analysis of interactions and optimise of selected input parameters and responses in this research.

\section{Results}

\section{Characteristics of picosecond laser ablation of $\mathrm{H13}$}

The focal point of the laser beam is influenced by the accuracy of the vertical position of the laser head. This affects the beam diameter which controls the kerf width for single line scans. Shown in Fig. 4 are the variations observed with the laser beam radius

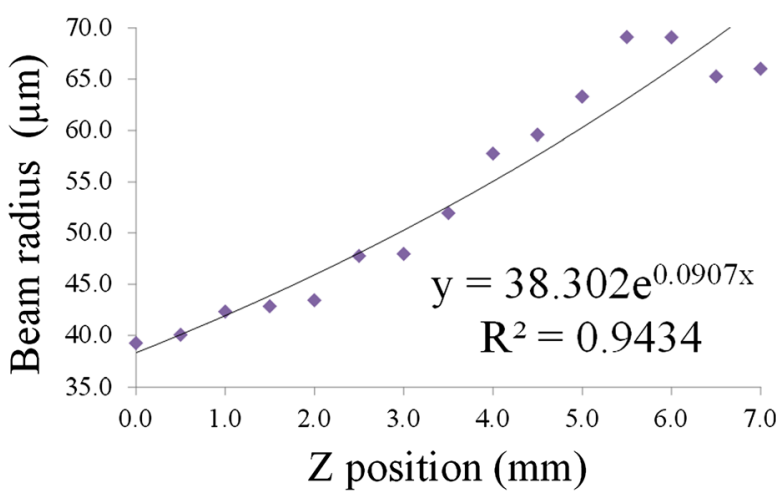

Fig. 4 Plot of corresponding laser beam radius (half beam diameter) to vertical variations ( $Z$ position) of the galvo head, for $\mathrm{H} 13$ ablation 
(half beam diameter) at a range of vertical distances from the target surface when the laser beam was focused on the target surface at " 0.0 ".

From the exponential fit of the experimental data a relationship was derived as:

$$
\mathrm{y}=38.302 \mathrm{e}^{0.0907 x}
$$

Therefore

$$
\mathrm{x}=\frac{\ln (\mathrm{y} / 38.302)}{0.0907}
$$

where $x$ represents the ' $z$ position' $(\mathrm{mm})$, while $y$ is the beam waist $(\mu \mathrm{m})$.

A linear fit of the graph of ablation rate versus 'Ln fluence' was generated for an estimation of the ablation threshold and the effective absorption length, in compliance with the general phenomenological Beer's model (covered in the section below) of laser ablation, as shown in Fig. 5.

Data generated from the picosecond laser ablation of $\mathrm{H} 13$ experiments are presented in Table 3. Five sets of depth measurements were collected using a LEICA optical microscope, with averages and standard errors calculated accordingly.

During the $\mathrm{H} 13$ ablation experiments, the pulse frequency was set at $400 \mathrm{kHz}$, laser scanning speed at $5000 \mathrm{~mm} / \mathrm{s}$ (i.e., $300 \mathrm{~m} / \mathrm{min}$ ), whilst varying the average laser power input. Each groove machined was scanned at 2000 passes and their average depths were recorded in Table 3. There was noticeable increase in depth with increasing average power. The graph in Fig. 5 illustrates the dependence of ablation depth on the laser fluence. The linear relationship signifies that ablation depth is primarily influenced by laser fluence, at the particular pulse frequency. There are two distinctive slopes: one representing slow ablation at lower fluences and one representing rapid ablation at higher laser fluences. Table 4 shows the ablation data deduced from Fig. 5.

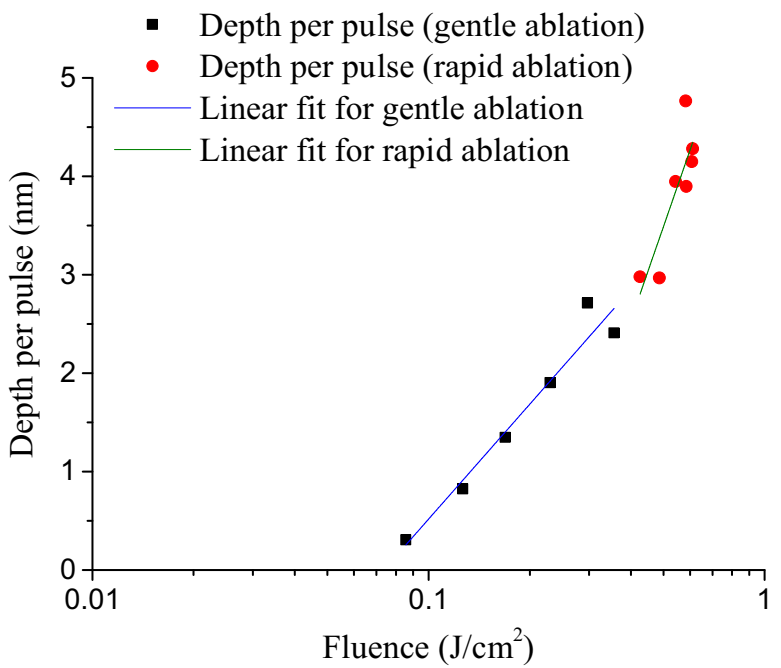

Fig. 5 The ablation characteristics graph for H13 (PS laser at $28.6 \mathrm{~W} ; 400 \mathrm{kHz} ; 5000 \mathrm{~mm} / \mathrm{s} ; 2000$ passes) with linear fits 
Table 3 H13 ablation data and calculations: $400 \mathrm{kHz} ; 5000 \mathrm{~mm} / \mathrm{s} ; 2000$ passes

\begin{tabular}{lllllllll}
\hline $\begin{array}{l}\text { Ave. } \\
\text { power } \\
(\mathrm{W})\end{array}$ & $\begin{array}{l}\text { Peak } \\
\text { power } \\
(\mathrm{MW})\end{array}$ & $\begin{array}{l}\text { Pulse } \\
\text { energy } \\
(\mathrm{mJ})\end{array}$ & $\begin{array}{l}\text { Fluence } \\
\left(\mathrm{J} / \mathrm{cm}^{2}\right)\end{array}$ & $\begin{array}{l}\text { No. } \\
\text { passes }\end{array}$ & $\begin{array}{l}\text { Total No. } \\
\text { pulses }\end{array}$ & $\begin{array}{l}\text { Ave. } \\
\text { depth } \\
(\mu \mathrm{m})\end{array}$ & $\begin{array}{l}\text { Std. } \\
\text { error }\end{array}$ & $\begin{array}{l}\text { Depth per } \\
\text { pulse }(\mathrm{nm})\end{array}$ \\
\hline 4.2 & 10.50 & 10.50 & 0.09 & 2000 & 20,000 & 6.15 & 0.11 & 0.3 \\
6.2 & 15.50 & 15.50 & 0.13 & 2000 & 20,000 & 16.49 & 0.13 & 0.8 \\
8.3 & 20.75 & 20.75 & 0.17 & 2000 & 20,000 & 26.96 & 0.56 & 1.4 \\
11.3 & 28.25 & 28.25 & 0.23 & 2000 & 20,000 & 38.05 & 0.09 & 1.9 \\
14.6 & 36.50 & 36.50 & 0.30 & 2000 & 20,000 & 54.24 & 0.35 & 2.7 \\
17.5 & 43.75 & 43.75 & 0.36 & 2000 & 20,000 & 48.17 & 1.12 & 2.4 \\
20.9 & 52.25 & 52.25 & 0.43 & 2000 & 20,000 & 59.6 & 0.53 & 3.0 \\
23.9 & 59.75 & 59.75 & 0.49 & 2000 & 20,000 & 59.36 & 1.4 & 3.0 \\
26.7 & 66.75 & 66.75 & 0.54 & 2000 & 20,000 & 78.97 & 0.68 & 4.0 \\
28.7 & 71.75 & 71.75 & 0.58 & 2000 & 20,000 & 77.98 & 1.37 & 3.9 \\
30.0 & 75.00 & 75.00 & 0.61 & 2000 & 20,000 & 85.62 & 0.79 & 4.3 \\
29.8 & 74.50 & 74.50 & 0.61 & 2000 & 20,000 & 83.00 & 1.21 & 4.2 \\
28.6 & 71.50 & 71.50 & 0.58 & 2000 & 20,000 & 95.33 & 0.07 & 4.8 \\
\hline
\end{tabular}

The relationship between the ablation depth and laser fluences can be described by Beer-Lambert law [29, 30]:

$$
h=\frac{1}{\alpha} \ln \left(\frac{F}{F_{\tau}}\right)
$$

This could be re-arranged to give:

$$
h=\left(\frac{1}{\alpha}\right) \ln F-\left(\frac{1}{\alpha}\right) \ln F_{\tau}
$$

Where:

$\mathrm{h}$ is the ablation (etched) depth; $F$ the fluence $\left(\mathrm{J} / \mathrm{cm}^{2}\right)$ and $F_{T}$ the threshold fluence $\left(\mathrm{J} / \mathrm{cm}^{2}\right)$. $\alpha$ symbolised the absorption coefficient, while its inverse $\left(\frac{1}{a}\right)$ defined the optical penetration depth.

Table 4 Ablation threshold data from graph of 'Ln Fluence' for H13

\begin{tabular}{lllllll}
\hline & \multicolumn{2}{c}{ Intercept } & & Slope & & Statistics \\
\cline { 2 - 5 } \cline { 5 - 6 } & Value & $\begin{array}{c}\text { Standard } \\
\text { deviation }\end{array}$ & Value & $\begin{array}{c}\text { Standard } \\
\text { deviation }\end{array}$ & Adj. R-square \\
\hline $\begin{array}{c}\text { Depth per pulse (slow ablation } \\
\text { regime) nm. }\end{array}$ & 4.01 & 0.28 & 1.52 & 0.13 & 0.99 \\
$\begin{array}{c}\text { Depth per pulse (rapid ablation } \\
\text { regime) nm. }\end{array}$ & 5.39 & 0.35 & 2.49 & 0.40 & 0.80 \\
\hline
\end{tabular}


With respect to the equation of a line;

$$
y=m x+c
$$

where $c$ represented the line of intercept and $m$ the slope, and by matching like terms (from the linearly fitted graphs), it implied that;

$$
\begin{aligned}
& h=y \\
& m=\left(\frac{1}{\alpha}\right) ; c=-\left(\frac{1}{\alpha}\right) \ln F_{\tau}
\end{aligned}
$$

Therefore:

$$
F_{\tau}=e^{-[(c)(-\alpha)]}
$$

The absorption coefficient, a material dependent quantity with respect to the interacting laser beam wavelength, expressed how well light can penetrate a specific material before being absorbed and thermal loading $(\gamma)$ expressed as $\mathrm{J} /$ $\mathrm{cm}^{3}$

$$
\gamma=\alpha F_{\tau}
$$

By applying the respective equations the various ablation rates are calculated. The H13 specimen investigated within the specified range of laser fluences, exhibited two linear fitted ablation rate regimes (slow and rapid) and ablation thresholds as similarly reported by various researchers [12, 31-35].

Using the above equations and the experimental data, the following can be obtained as shown in Table 5 .

Figure 6 compares three specimens processed with different laser energy density (fluence), with specimen (c) being most affected by heat affected zones (HAZ).

Typical picosecond laser patterned grooves are shown in Fig. 7, with dimensions presented in Table 6, showing heat affected zones (HAZ).

The capacity of the picosecond pulsed laser to achieve high peak power intensity (up to $10^{8} \mathrm{~W} / \mathrm{cm}^{2}$ ) enhances the material removal rate primarily by express surface vaporisation, hence it is a convenient strategy for laser processing with minor HAZ $[5,36-39]$.

Table 5 Calculated ablation data for H13

\begin{tabular}{lllll}
\hline & $\begin{array}{l}\text { Optical penetration } \\
\text { depth }(1 / \alpha) \mathrm{nm}\end{array}$ & $\begin{array}{l}\text { Absorption } \\
\text { coefficient }(\alpha) \mathrm{cm}^{-1}\end{array}$ & $\begin{array}{l}\text { Threshold fluence } \\
\left(\mathrm{F}_{\mathrm{T}}\right) \mathrm{mJ} / \mathrm{cm}^{-2}\end{array}$ & $\begin{array}{l}\text { Thermal loading } \\
(\gamma) \mathrm{kJ} / \mathrm{cm}^{-3}\end{array}$ \\
\hline $\begin{array}{c}\text { Slow ablation regime } \\
\left(70-119 \mathrm{~mJ} / \mathrm{cm}^{3}\right)\end{array}$ & 1.5 & $6,593,479$ & 70 & 467.38 \\
$\begin{array}{c}\text { Rapid ablation regime } \\
\left(120-610 \mathrm{~mJ} / \mathrm{cm}^{3}\right)\end{array}$ & 2.5 & $4,009,768$ & 120 & 462.28 \\
\hline
\end{tabular}




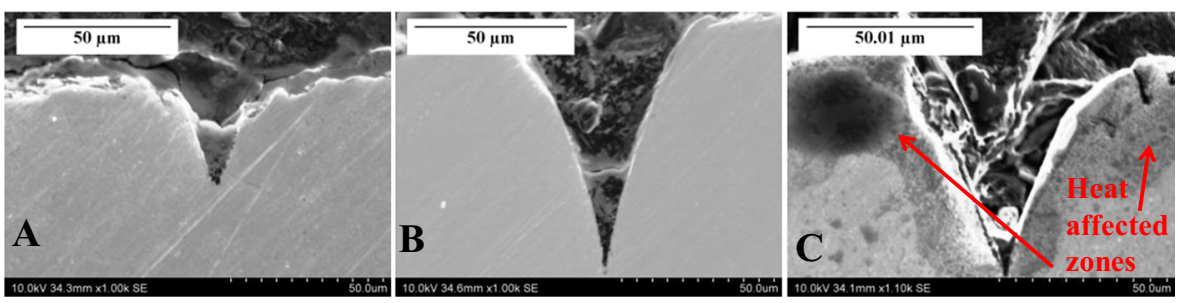

Fig. 6 Optical microscopic (SEM) images of $\mathrm{H} 13$ samples after chemical etching with $2 \%$ Nital for $10 \mathrm{~s}$ : (a) $148 \mathrm{~mJ} / \mathrm{cm}^{2}$ (b) $241 \mathrm{~mJ} / \mathrm{cm}^{2}$ and (c) $420 \mathrm{~mJ} / \mathrm{cm}^{2}$ (with noticeable HAZ)

\section{Picosecond laser patterning on $\mathrm{H13}$ and pattern transfer to ABS surface through injection moulding}

With the knowledge acquired from the ablation data for $\mathrm{H} 13$ tool steel, various micropatterns were fabricated on $\mathrm{H} 13$ flat sheets and inserted as primary tools for injection moulding. The reverse structures were transferred to ABS moulded samples during injection moulding. Hence, PS laser fabricated micro-channels (v-grooves) became riblets on moulded ABS (Fig. 8).

Figure 9 shows data for the surface roughness for the picosecond laser machined $\mathrm{H} 13$ groove bottom end $(\mathrm{Ra}=3.4 \mu \mathrm{m})$ and the replicated $\mathrm{ABS}$ riblet tip $(\mathrm{Ra}=2.9 \mu \mathrm{m})$. The replicated ABS surface is slightly smoother possibly due to non-contact with the groove machined on the H13, as observed in Fig. 10.

The variation between the picosecond laser patterned H13 secondary tool insert and the replicated riblets on ABS, is shown in Fig. 10. An average surface to bottom depth of $202 \mu \mathrm{m}$ was achieved on (a) H13, with corresponding bump height of $171 \mu \mathrm{m}$ on (b) ABS representing $85 \%$ total depth transferred.

Conical patterns on $\mathrm{H} 13$ were replicated on ABS to form converse shapes as shown in Fig. 11. The ABS samples were then analysed for size and quality (transfer fidelity), after the specimens were gold-plated $(20 \mathrm{~nm}$ film) for better optical image profiling.

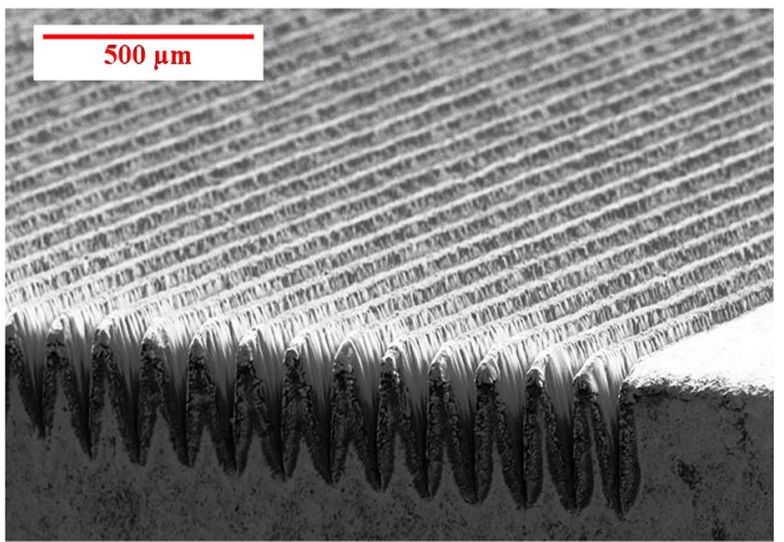

Fig. 7 An SEM image of picosecond laser uniformly structured H13 micro-grooves with an average peak to peak distance of $121 \mu \mathrm{m}$ 
Table 6 Picosecond (PS) laser structured H13 micro-grooves dimensions ( $\mu \mathrm{m})$

\begin{tabular}{lllll}
\hline & Peak -to-peak & Depth of groove & HAZ & Kerf width \\
\hline Average & 118.3 & 329.1 & 19.0 & 87.0 \\
Error & 2.6 & 1.3 & 0.3 & 1.4 \\
\hline
\end{tabular}

\section{Statistical modelling for H13 ablation using design of experiment (response surface model)}

To understand picosecond interaction with H13 tool steel, a statistical model of the process was generated using Design Expert ${ }^{\circledR}$ Software (central composite design). Real

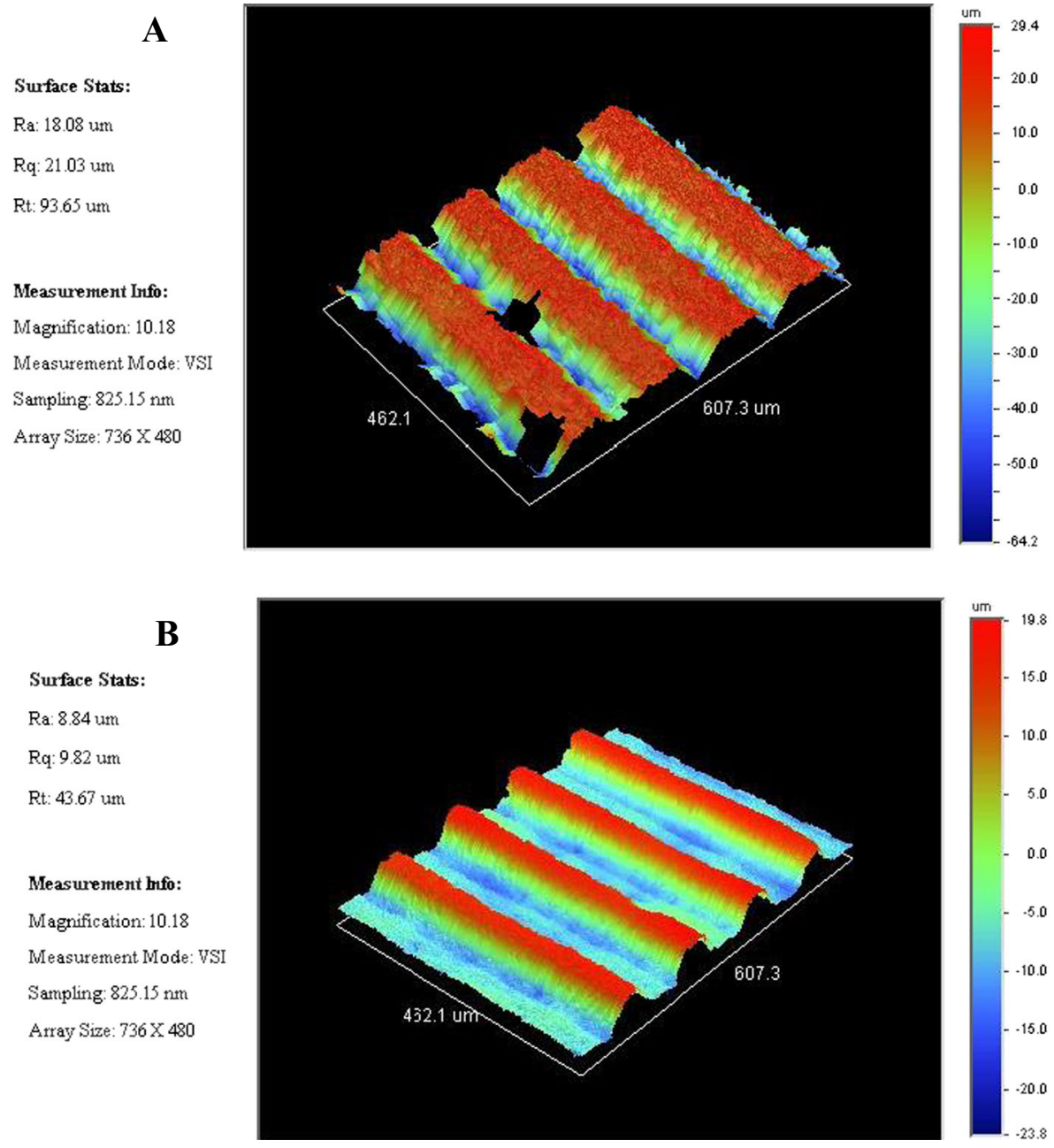

Fig. 8 Wyko image profiles: (a) picosecond laser textured H13 micro-grooves, (b) ABS riblets transferred from $\mathrm{H} 13$ flat sheets, through injection moulding 


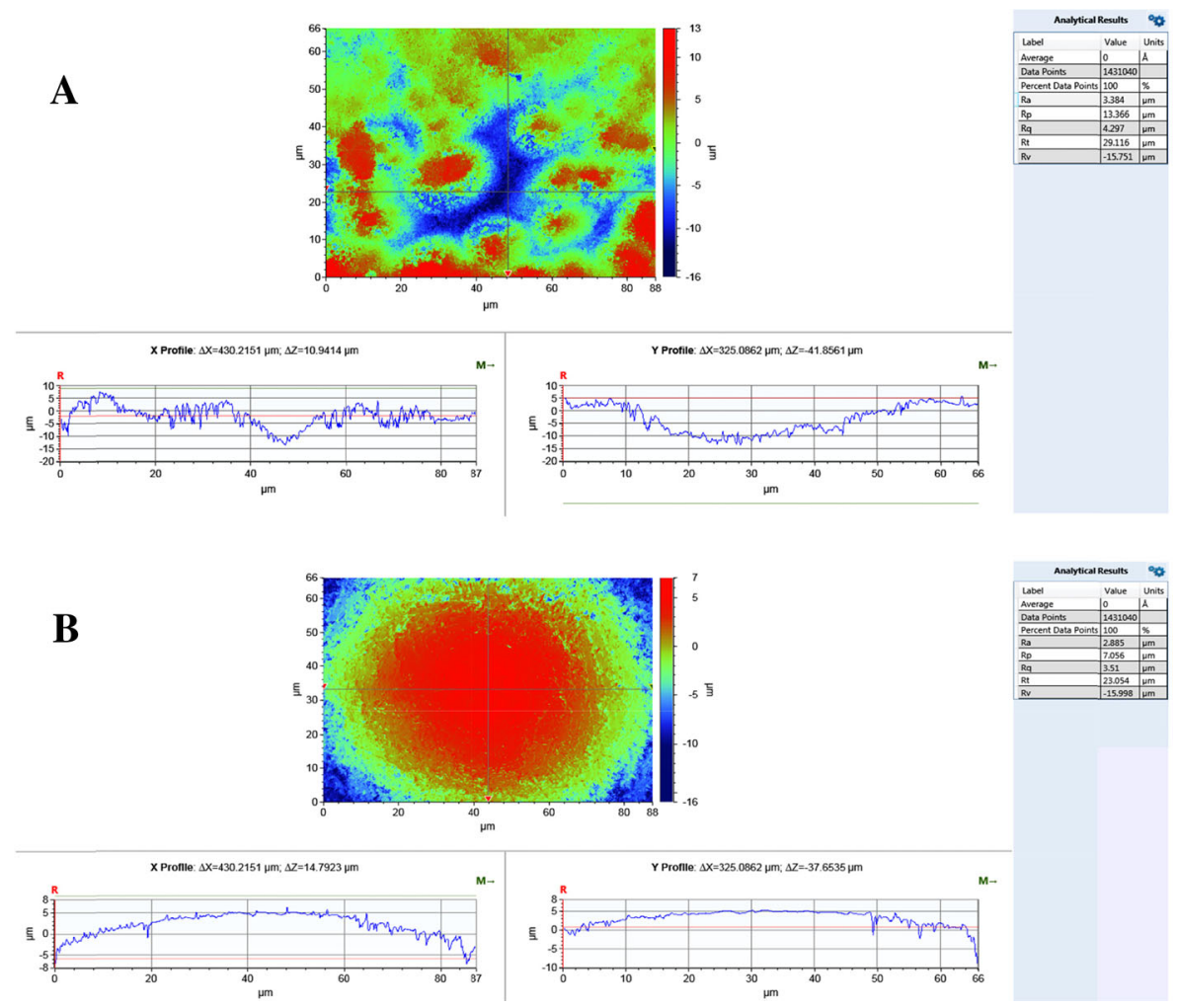

Fig. 9 Wyko roughness profiles: (a) picosecond laser textured H13 micro-grooves bottom end, (b) tip of micro-pattern on ABS transferred from $\mathrm{H} 13$ flat sheets, through injection moulding

factors considered were laser processing speed, number of passes and laser fluence, while the measured responses were depth of cut, kerf width and heat affected zone

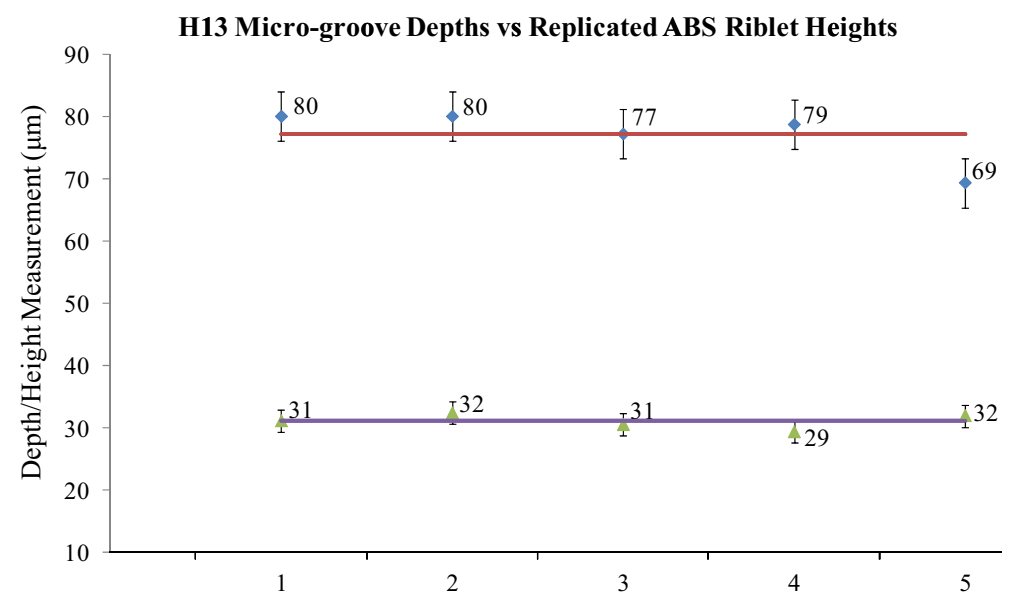

Fig. 10 A quantitative plot of picosecond laser patterned H13 (flat plate) micro-grooves, replicated ABS to form riblets, through injection moulding 


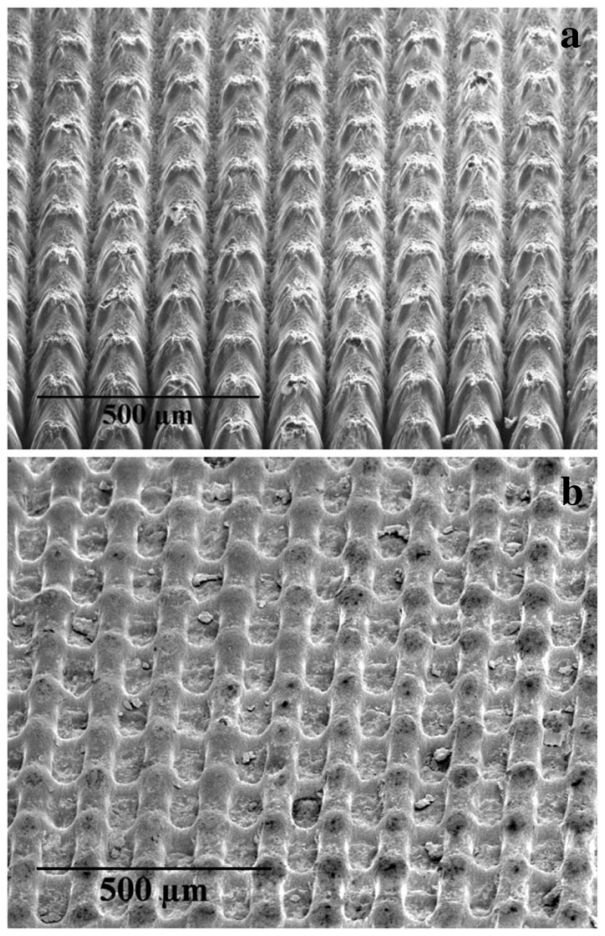

Fig. 11 SEM images of (a) H13 samples machined with picosecond laser (processed at $59 \mathrm{~W} ; 500 \mathrm{kHz}$; $10,000 \mathrm{~m} / \mathrm{s}$ and $1500 \mathrm{scans})$ with highly repeatable conical patterns $(136 \mu \mathrm{m}$ by $110 \mu \mathrm{m}$ peak-peak length) replicated on (b) ABS to form inverse profiles (129 $\mu \mathrm{m}$ by $104 \mu \mathrm{m}$ peak-peak)

(HAZ). A fluence range of $0.22-0.32 \mathrm{~J} / \mathrm{cm}^{2}$ was considered by fixing the pulse frequency at $205 \mathrm{kHz}$ whilst varying the average power. These values were chosen from initial trials which showed higher material removal with less HAZ. Furthermore, with the laser used, dimensional integrity was unstable at processing speed values above $2000 \mathrm{~mm} / \mathrm{s}$, hence the range considered in the model was 1000-2000 mm/s. Laser machining was done over a $30 \mathrm{~mm}$ scanning length. A summary of the experimental design was as shown in Table 7.

\section{Depth of Cut}

The perturbation plot demonstrates the influence of the laser input/control parameters on depth of cut. The horizontal axis represents values of the control factors in coded form, while the vertical axis corresponds to values of 'depth of cut' as outcome. Variations in laser processing speed and number of passes are control factors with higher weight on the depth of cut. While the residuals plot illustrates the normal probability data points approximated along a straight line signifying no evident obscurity with normality. The predicted data for the model were in close agreement with the actual data from experiment, considering processing and data acquisition errors. All these graphs are presented in Fig. 12.

The interaction plots for this model (within fluence range of $220-320 \mathrm{~mJ} / \mathrm{cm}^{2}$ ) as presented in Fig. 13, confirmed relative increase in depth of cut, with corresponding 
Table 7 Design summary for H13 ablation using central composite design

\begin{tabular}{|c|c|c|c|c|c|c|c|c|}
\hline \multicolumn{2}{|c|}{ Study type } & \multicolumn{2}{|c|}{ Response surface } & \multicolumn{5}{|l|}{ Runs $=20$} \\
\hline \multicolumn{2}{|c|}{ Initial design } & \multicolumn{7}{|c|}{ Central composite } \\
\hline \multicolumn{2}{|c|}{ Design model } & \multicolumn{3}{|c|}{ Quadratic } & \multicolumn{4}{|l|}{ Numeric type } \\
\hline Factor & Name & Units & Low Actual & High Actual & Low Coded & High Coded & Mean & Std. Dev. \\
\hline A & Speed & $\mathrm{mm} / \mathrm{s}$ & 1000 & 2000 & -1 & 1 & 1500 & 397.6 \\
\hline B & No. of passes & & 1000 & 2000 & -1 & 1 & 1500 & 397.6 \\
\hline $\mathrm{C}$ & Fluence & $\mathrm{J} / \mathrm{cm}^{2}$ & 0.22 & 0.32 & -1 & 1 & 0.27 & 0.04 \\
\hline
\end{tabular}

increase in number of laser scans, for a particular scanning speed $(1500 \mathrm{~mm} / \mathrm{s})$, while an increase in the laser scanning speed had a resultant decrease in the etch rate, for a fixed number of laser scans. The related contour and surface plots are respectively presented in Fig. 14.

The equation in terms of actual factors can be found as:

Depth of $\operatorname{cut}(\mu \mathrm{m})=$

$126.33-4.00 * 10^{-2}(\mathrm{~A})+9.13 * 10^{-2}(\mathrm{~B})-800.38(\mathrm{C})-3.93 * 10^{-6}(\mathrm{AB})-3.16^{*} 10^{-2}(\mathrm{AC})-8.13 * 10^{-2}(\mathrm{BC})$

$+1.34 * 10^{-5}\left(\mathrm{~A}^{2}\right)-1.35^{*} 10^{-5}\left(\mathrm{~B}^{2}\right)+1833.87\left(\mathrm{C}^{2}\right)$

Where: $\mathrm{A}=$ Speed; $\mathrm{B}=$ No. of passes; and $\mathrm{C}=$ Fluence.

This model indicates that speed and number passes are the major determinant factors that will influence the etch rate of $\mathrm{H} 13$ tool steel considered.

\section{Kerf width}

The perturbation plot indicated reduced kerf width with increased scanning speed, for a specific set of laser processing parameters. The predicted and experimental data for kerf width were within their respective value ranges, while the surface plots of shows how kerf widths responded to the actual laser processing parameters when compared with predicted data. These plots are graphically represented in Fig. 15, while Fig. 16 shows various surface plots the respective responses of kerf widths to actual laser processing factors of speed, number of laser scans (at fixed fluence of $0.27 \mathrm{~J} / \mathrm{cm}^{2}$ ), and fluence. From this result it seems to indicate that the scanning speed has a nominating effect on the kerf width while the laser beam spot size is kept constant.

The empirical equation relating kerf width with laser processing parameters is:

$\operatorname{Kerf}$ width $(\mu \mathrm{m})=$

$21.85-1.24 * 10^{-2}(\mathrm{~A})+3.42 * 10^{-2}(\mathrm{~B})+229.63(\mathrm{C})+9.99 * 10^{-6}(\mathrm{AB})-3.93 * 10^{-2}(\mathrm{AC})-2.33 * 10^{-2}(\mathrm{BC})$ $+4.47 * 10^{-7}\left(\mathrm{~A}^{2}\right)-1.31 * 10^{-5}\left(\mathrm{~B}^{2}\right)-247.13\left(\mathrm{C}^{2}\right)$

When considering kerf width, number of laser scans at a particular fluence was the most sensitive factor in this model during processing of $\mathrm{H} 13$ tool steel. 


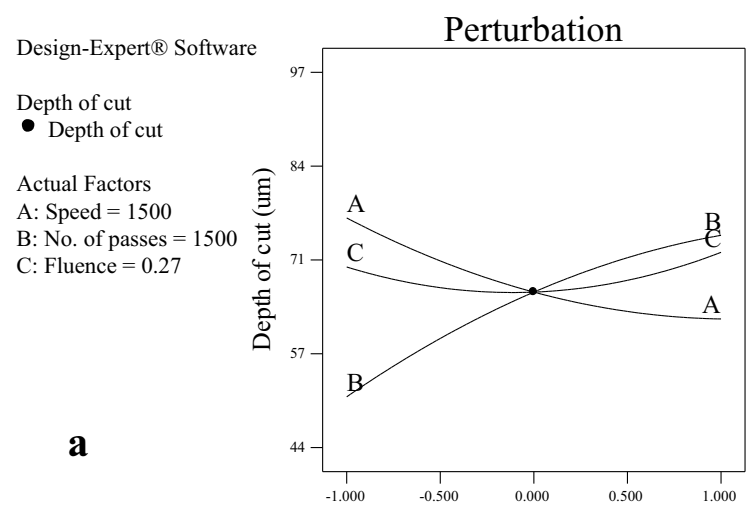

Deviation from Reference Point (Coded Units)
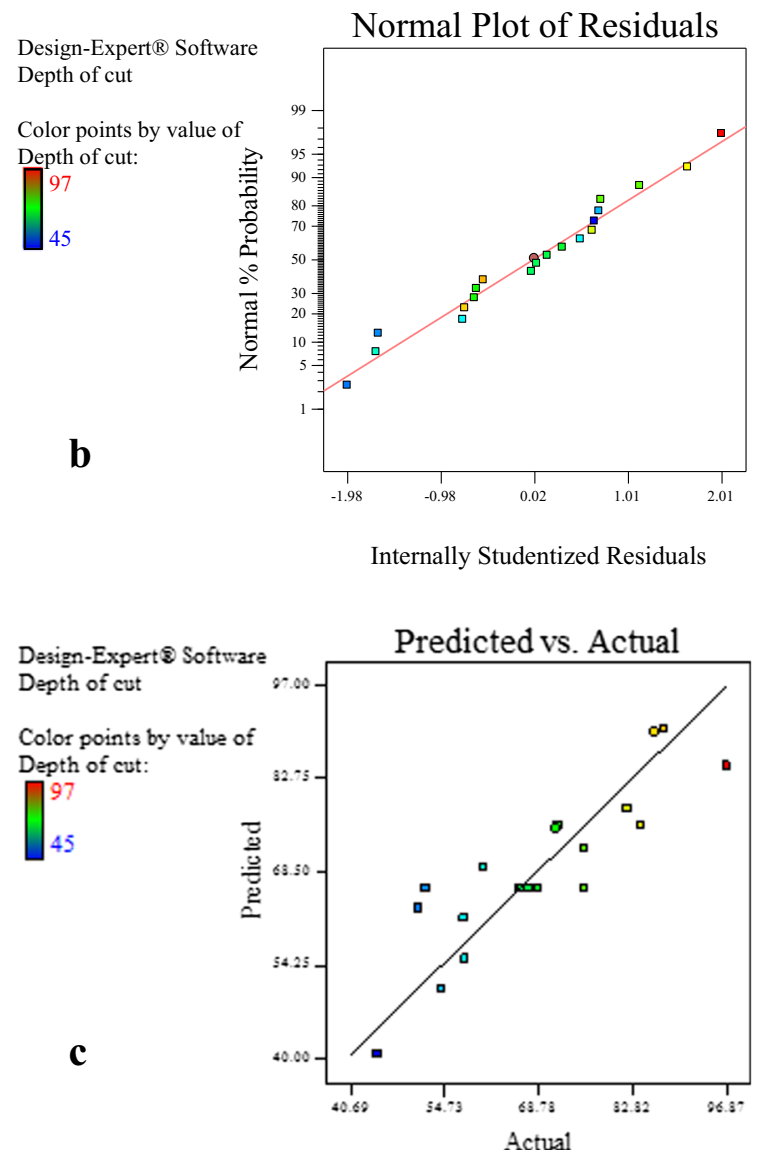

Fig. 12 Respective graphs of: (a) the perturbation plot of interacting factors, (b) normal probability plot of residuals, and (c) comparative plot of predicted versus actual data, for the depth of cut model 


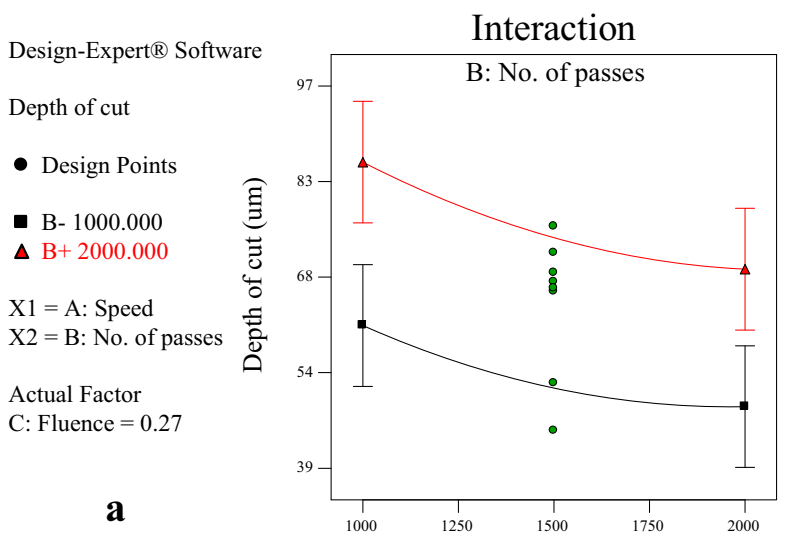

A: Speed $(\mathrm{mm} / \mathrm{s})$

Design-Expert ${ }^{\circledR}$ Software

Interaction

Depth of cut

- Design Points

- C- 0.220

$\Delta \mathrm{C}+0.320$

$\mathrm{X} 1=\mathrm{A}:$ Speed

$\mathrm{X} 2=\mathrm{C}$ : Fluence

Actual Factor

B: No. of passes $=1500$

b

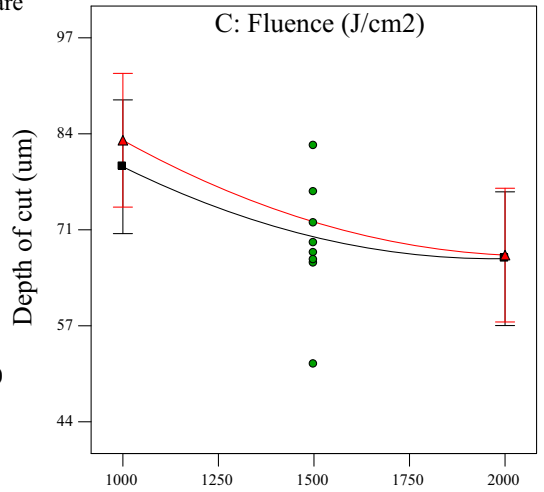

A: Speed $(\mathrm{mm} / \mathrm{s})$

Interaction

Design-Expert ${ }^{\circledR}$ Software

Depth of cut

- Design Points

- C- 0.220

$\Delta \mathrm{C}+0.320$

$\mathrm{X} 1=\mathrm{B}$ : No. of passes

$\mathrm{X} 2$ = C: Fluence

Actual Factor

A: Speed $=1500$

c

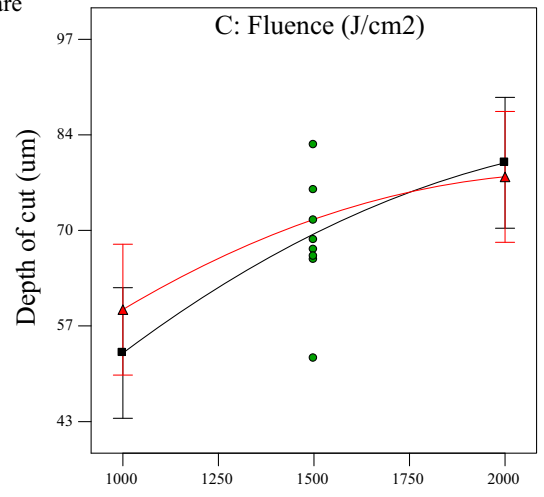

B: No. of passes

Fig. 13 Interaction plots in relation to depth of cut; (a) speed and number of passes considered at a fluence of $270 \mathrm{~mJ} / \mathrm{cm}^{2}$, (b) laser scanning speed and fluence, (c) number of laser scans and fluence 

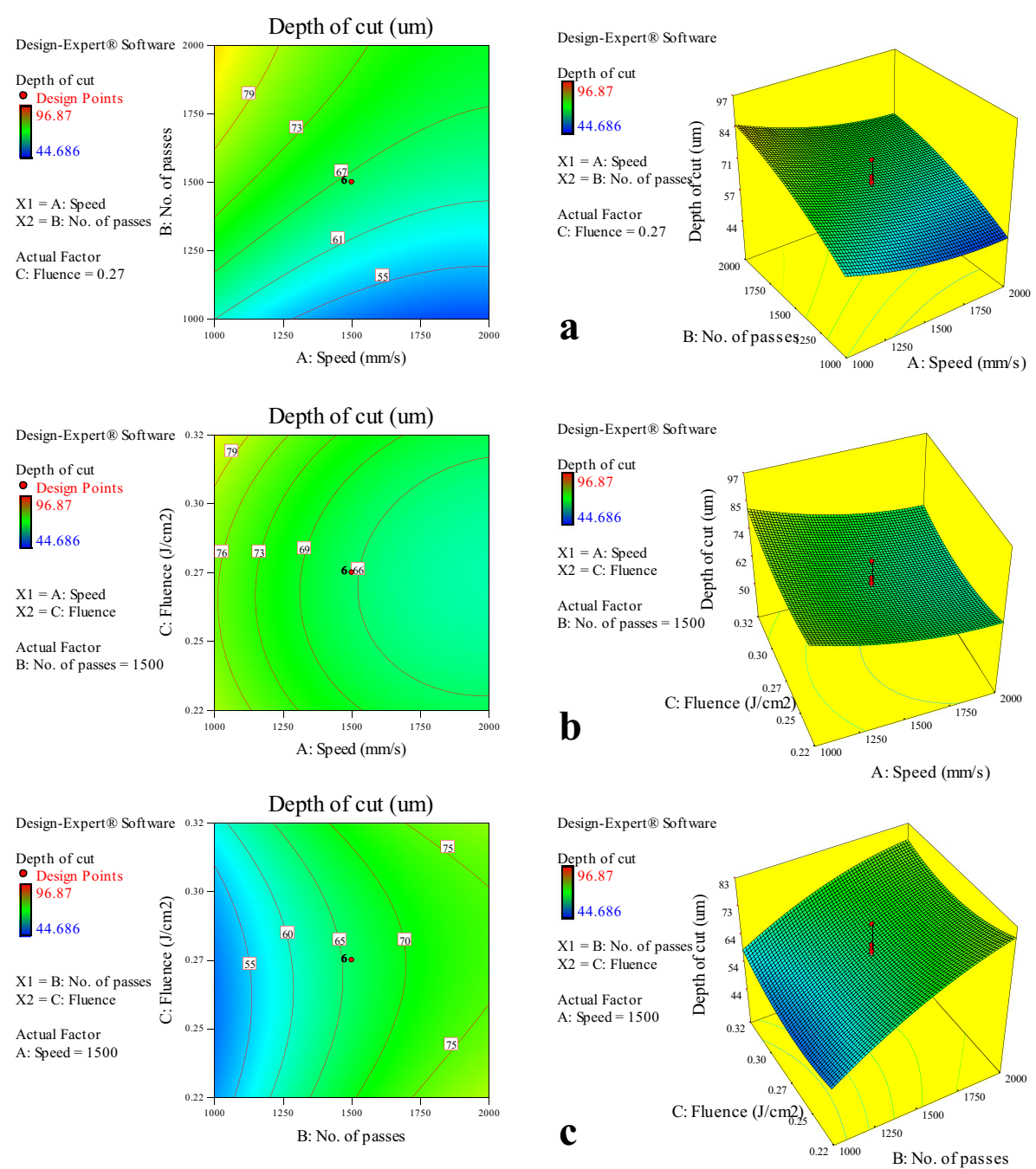

Fig. 14 Contour and surface plots with respective depth of cut as a response to; (a) speed and number of passes considered at a fluence of $270 \mathrm{~mJ} / \mathrm{cm}^{2}$, (b) speed and fluence, (c) number of laser scans and fluence

\section{Heat affected zone (HAZ)}

For the picosecond laser processing of H13 tool steel, heat affected zones (HAZ) was most affected by increasing laser fluence, according to the perturbation plot for the model, present in Fig. 17.

The model equation for the related HAZ in terms of the actual factors is:

$$
\begin{aligned}
\operatorname{HAZ}(\mu \mathrm{m}) & =32.93+3.44 * 10^{-2}(\mathrm{~A})+3.12^{*} 10^{-2}(\mathrm{~B})-499.75(\mathrm{C})-7.81 * 10^{-6}(\mathrm{AB})-5.89 * 10^{-3}(\mathrm{AC}) \\
& -6.11 * 10^{-3}(\mathrm{BC})-6.45^{*} 10^{-6}\left(\mathrm{~A}^{2}\right)-5.06^{*} 10^{-6}(\mathrm{~B})+1151.95(\mathrm{C})
\end{aligned}
$$




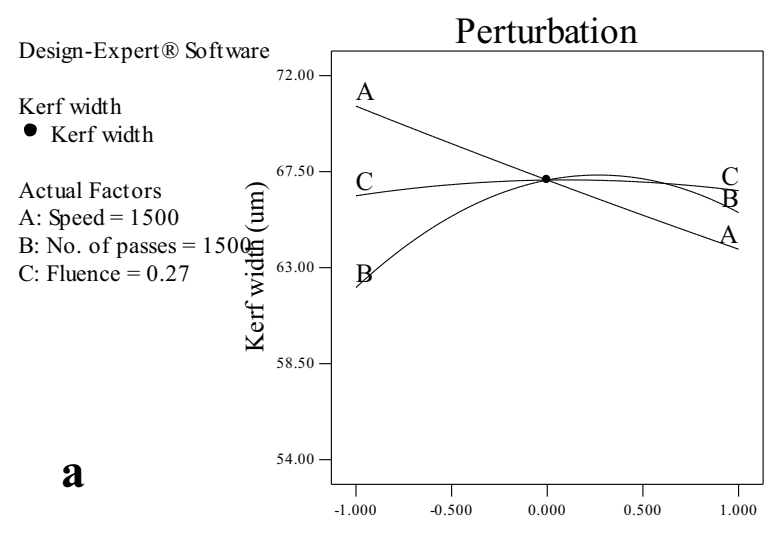

Deviation from Reference Point (Coded Units)
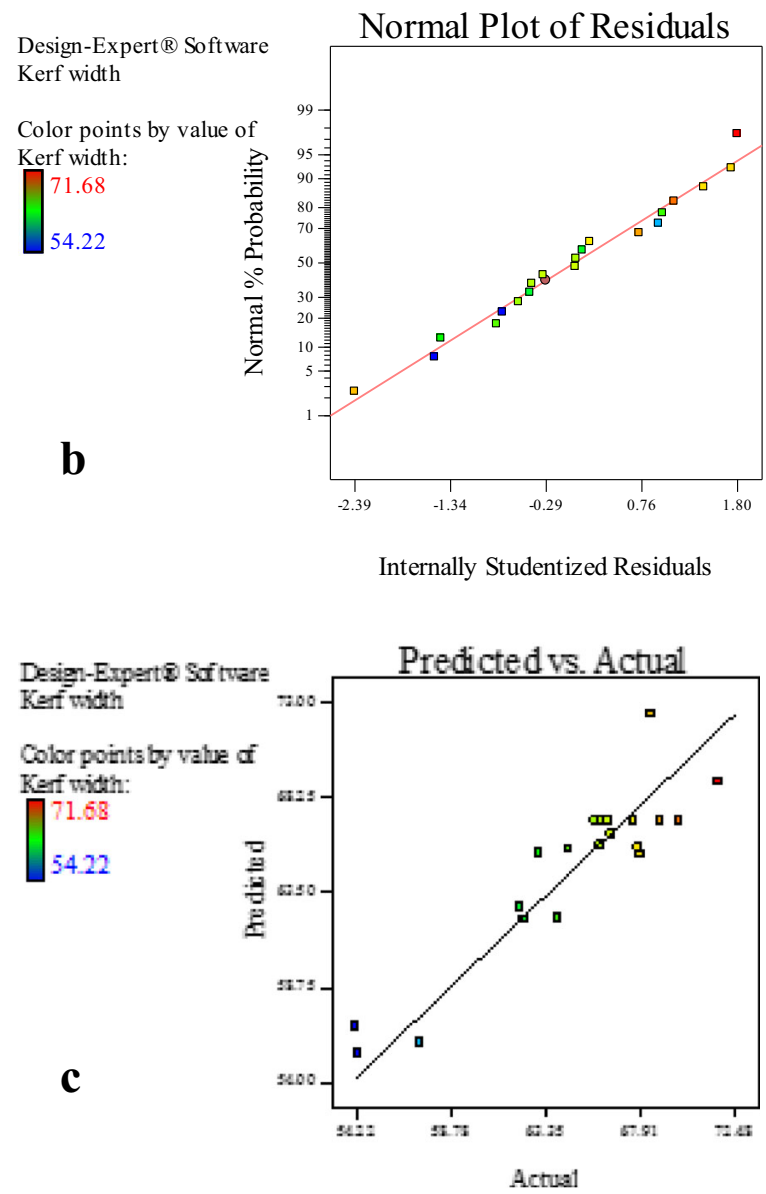

Fig. 15 Kerf width model graphs; (a) the perturbation plot of interacting factors, (b) normal probability plot of residuals, and (c) plot of predicted versus actual data 

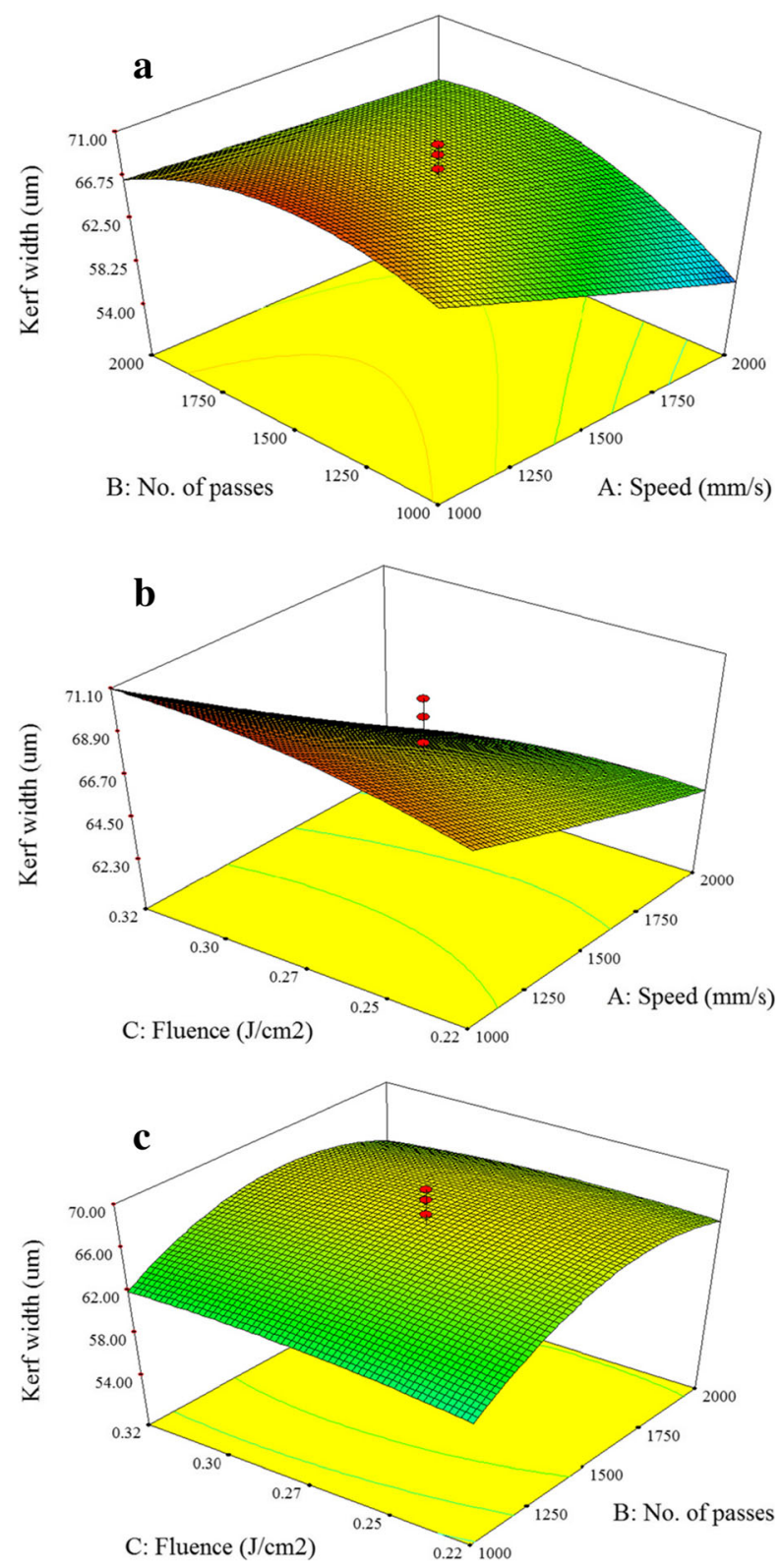

Fig. 16 3D plots for kerf widths as response to actual factors; (a) speed and number of laser passes at fixed fluence of $0.27 \mathrm{~J} / \mathrm{cm}^{2}$, (b) laser scanning speed and fluence, (c) number of laser scans (passes) and fluence

\section{Model optimisation}

The model was constrained as shown in Table 8, according to level of significance to the laser processing parameters in affecting the depth of cut with minimal HAZ considerations. The predicted solutions for the model are presented in Table 9. 


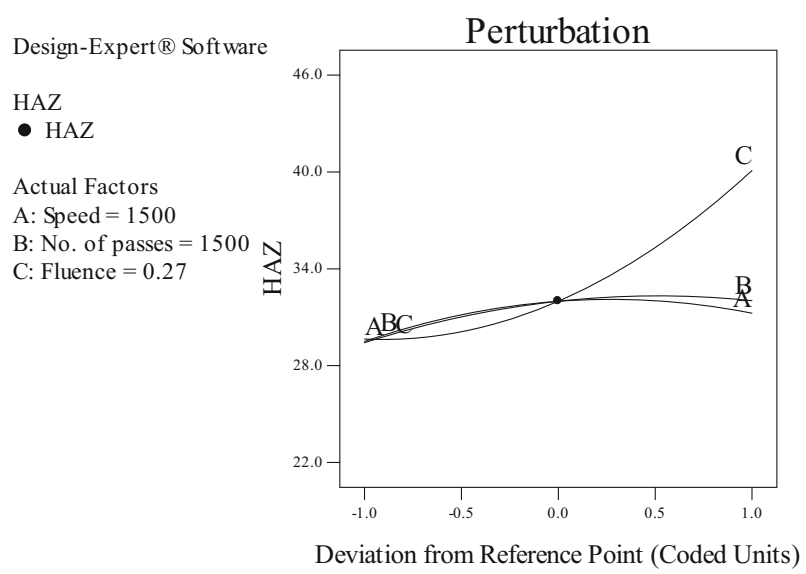

Fig. 17 Perturbation plot representative of how well actual factors affect HAZ

Starting with a selected regime, 19 optimal solutions were generated from the model according to the combined desirability of the laser processing parameters considered. Desirability is a mathematical function to determine the optimal solution considering all the set goals, as described by Myers and Montgomery in p. 244 of "Response Surface Methodology" [23].

Desirability is a multiple response method which is used to formulate an objective function $D(X)$ to reflect the desirable ranges for each response $\left(d_{i}\right)$. The simultaneous objective function can be expressed as a geometric mean of all the transformed responses [23]:

$$
D=\left(d_{1}^{r_{1}} X d_{1}^{r_{2}} X \ldots X d_{1}^{r_{n}}\right) \overline{\frac{1}{\sum r_{i}}}=\left(\prod_{i=1}^{n} d_{1}^{r_{l}}\right) \overline{\sum^{1} r_{i}}
$$

where $n$ represents the number of responses under consideration; $r_{i}$ is a measure of importance the response (from most important with a value of 5, to least important with a value of 1).

To optimise the model, the respective laser fluences $\left(0.22-0.32 \mathrm{~J} / \mathrm{cm}^{2}\right)$ considered in the model in relation to speed and number of laser scans, were analysed from the graphs in Fig. 18. The yellow portions (more within the lowest fluence regime of $0.22 \mathrm{~J} / \mathrm{cm}^{2}$ )

Table 8 Model optimisation design constraints

\begin{tabular}{lllllll}
\hline Name & Goal & $\begin{array}{l}\text { Lower } \\
\text { Limit }\end{array}$ & $\begin{array}{l}\text { Upper } \\
\text { Limit }\end{array}$ & $\begin{array}{c}\text { Lower } \\
\text { Weight }\end{array}$ & $\begin{array}{l}\text { Upper } \\
\text { Weight }\end{array}$ & Importance \\
\hline Speed $(\mathrm{mm} / \mathrm{s})$ & maximize & 1000 & 2000 & 1 & 1 & 5 \\
No. of passes & maximize & 1000 & 2000 & 1 & 1 & 5 \\
Fluence $\left(\mathrm{J} / \mathrm{cm}^{2}\right)$ & minimize & 0.22 & 0.32 & 1 & 1 & 3 \\
Depth of cut & in range & 44.69 & 96.87 & 1 & 1 & 5 \\
HAZ & minimize & 23 & 30 & 1 & 1 & 2 \\
\hline
\end{tabular}


Table 9 Model optimisation solutions

\begin{tabular}{|c|c|c|c|c|c|c|}
\hline Number & $\begin{array}{l}\text { Speed } \\
(\mathrm{mm} / \mathrm{s})\end{array}$ & $\begin{array}{l}\text { No. of } \\
\text { passes }\end{array}$ & $\begin{array}{l}\text { Fluence } \\
\left(\mathrm{J} / \mathrm{cm}^{2}\right)\end{array}$ & $\begin{array}{l}\text { Depth of } \\
\text { cut }(\mu \mathrm{m})\end{array}$ & $\begin{array}{l}\text { HAZ } \\
(\mu \mathrm{m})\end{array}$ & $\begin{array}{l}\text { Desirability } \\
(\%)\end{array}$ \\
\hline 1 & 2000 & 2000 & 0.22 & 75.6 & 27.3 & 88 \\
\hline 2 & 2000 & 2000 & 0.22 & 75.1 & 27.3 & 88 \\
\hline 3 & 2000 & 2000 & 0.22 & 74.9 & 27.3 & 88 \\
\hline 4 & 1994 & 2000 & 0.22 & 75.6 & 27.3 & 88 \\
\hline 5 & 2000 & 2000 & 0.22 & 74.7 & 27.2 & 88 \\
\hline 6 & 1988 & 2000 & 0.22 & 75.6 & 27.4 & 87 \\
\hline 7 & 2000 & 2000 & 0.23 & 74.1 & 27.2 & 87 \\
\hline 8 & 1974 & 2000 & 0.22 & 75.4 & 27.5 & 86 \\
\hline 9 & 2000 & 2000 & 0.23 & 73.2 & 27.3 & 86 \\
\hline 10 & 2000 & 2000 & 0.23 & 73.1 & 27.3 & 86 \\
\hline 11 & 2000 & 2000 & 0.24 & 72.6 & 27.3 & 85 \\
\hline 12 & 2000 & 2000 & 0.24 & 72.4 & 27.3 & 85 \\
\hline 13 & 1935 & 2000 & 0.22 & 74.9 & 27.8 & 83 \\
\hline 14 & 2000 & 1870 & 0.22 & 73.9 & 28.0 & 81 \\
\hline 15 & 2000 & 2000 & 0.27 & 69.4 & 28.9 & 69 \\
\hline 16 & 2000 & 1580 & 0.22 & 68.4 & 28.9 & 65 \\
\hline 17 & 2000 & 1571 & 0.22 & 68.2 & 29.0 & 64 \\
\hline 18 & 1549 & 2000 & 0.23 & 77.8 & 30.0 & 53 \\
\hline 19 & 1918 & 1269 & 0.22 & 60.0 & 29.2 & 47 \\
\hline
\end{tabular}

are regions of optimal laser processing of $\mathrm{H} 13$ tool steel, in order to minimise HAZ to $30 \mu \mathrm{m}$. The model considered laser micro-machining of $\mathrm{H} 13$ tool steel at $0.32 \mathrm{~J} / \mathrm{cm}^{2}$ not suitable within the defined constraints.

The most desirable solution (with bias to deepest depth of cut) was selected from the various options predicted, as indicated in Table 10:

An optimal solution with desirability of $88 \%$ corresponding to $75.6 \mu \mathrm{m}$ depth of cut was selected, and an experimental validation carried out for comparison. Figure 19 is a surface plot representative of the predicted desirability for depth of cut with minimal HAZ, considering the identified laser processing parameters in this model.

\section{Model validation - 'depth of cut'}

The model was validated by comparing the predicted data with experimental data (Table 11). By substituting in the appropriate values into equation:

$$
\begin{aligned}
& \text { Depth of } \operatorname{cut}(\mu \mathrm{m})=126.33-4.00 \mathrm{E}-2(2000)+9.13 \mathrm{E}-2(2000)-800.38(0.22)-3.93 \mathrm{E}-6(2000 * 2000) \\
& -3.16 \mathrm{E}-2(2000 * 0.22)-8.13 \mathrm{E}-2(2000 * 0.22)+1.34 \mathrm{E}-5(2000)^{2}-1.35 \mathrm{E}-5(2000)^{2}+1833.87(0.22)^{2}
\end{aligned}
$$



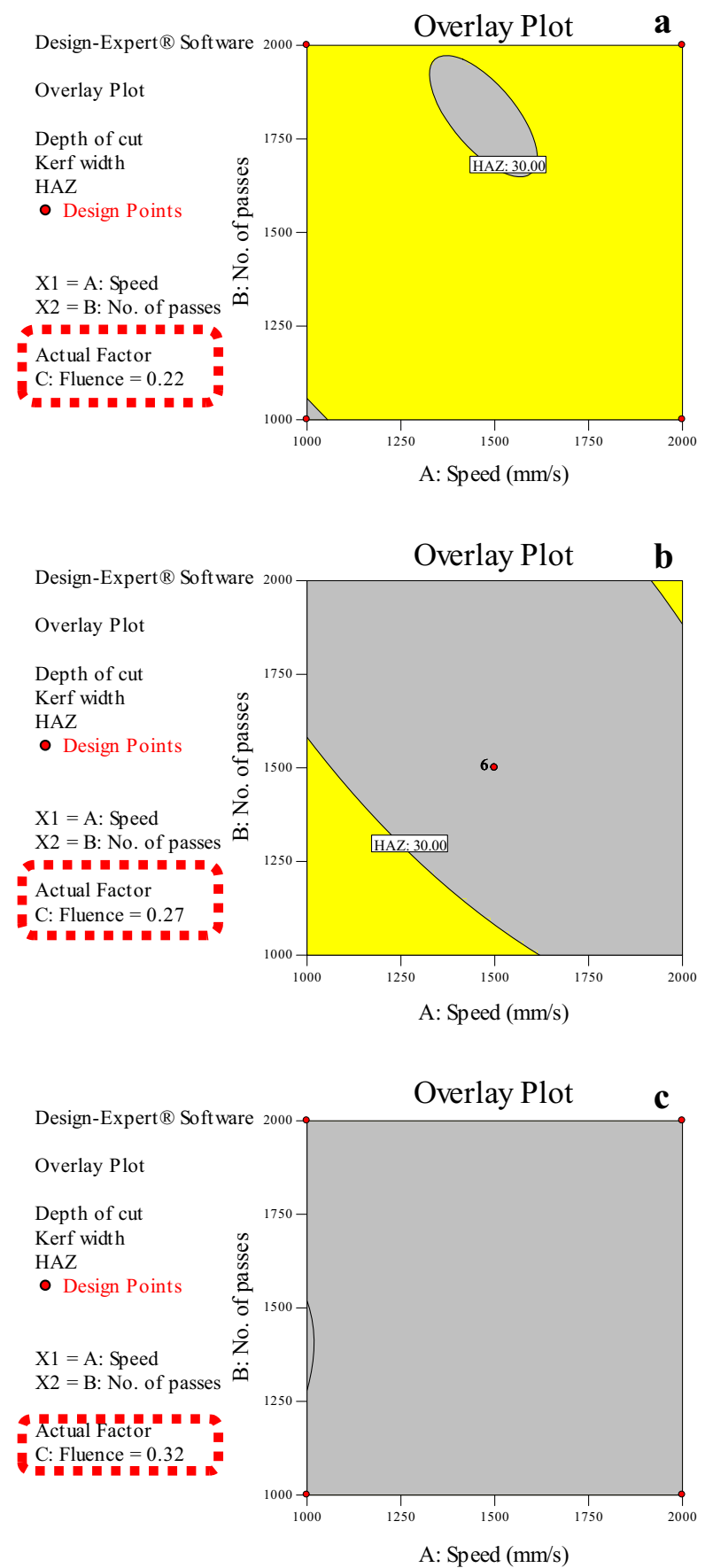

Fig. 18 Optimisation plots in respect of laser fluence regime applied in relation to speed and number of laser scans; (a) fluence $=0.22 \mathrm{~J} / \mathrm{cm}^{2}$, (b) fluence $=0.27 \mathrm{~J} / \mathrm{cm}^{2}$, (c) fluence $=0.32 \mathrm{~J} / \mathrm{cm}^{2}$

The predicted values for the selected parameters were used to validate the model and recorded in Table 9, showing $97 \%$ precision. 
Table 10 Most desirable predicted optimisation solution

\begin{tabular}{llllll}
\hline Speed $(\mathrm{mm} / \mathrm{s})$ & No. of passes & Fluence $\left(\mathrm{mJ} / \mathrm{cm}^{2}\right)$ & Depth of cut $(\mu \mathrm{m})$ & HAZ $(\mu \mathrm{m})$ & Desirability $(\%)$ \\
\hline 2000 & 2000 & 220 & 75.6 & 27.3 & 88 \\
\hline
\end{tabular}

\section{Discussion}

For a Gaussian mode laser, the beam waist can be represented in the equation below [5]:

$$
\mathrm{w}(\mathrm{z})^{2}=\mathrm{w}_{0}^{2}\left(1+\frac{\mathrm{z}^{2}}{\mathrm{~b}^{2}}\right)
$$

Where:

$\mathrm{W}_{0} \quad$ beam waist (i.e., smallest radius of laser beam)

$\mathrm{W}(\mathrm{z})$ beam radius at distance $\mathrm{z}$ from the beam waist

$\mathrm{z} \quad$ distance from the beam waist along beam axis; and

b Rayleigh length.

and

$$
\mathrm{b}=\frac{\pi \mathrm{W}_{0}^{2}}{\lambda}
$$

This implies that the longer the beam wavelength the higher beam divergence will be. By substituting the minimum half beam diameter value shown in Fig. 4 (with $\mathrm{W}_{0}=39 \mu \mathrm{m}$ and it is known that the laser wavelength is $\left.\lambda=1.064 \mu \mathrm{m}\right)$ into equation (15):

\section{Rayleigh length $\approx 5 \mathrm{~mm}$}

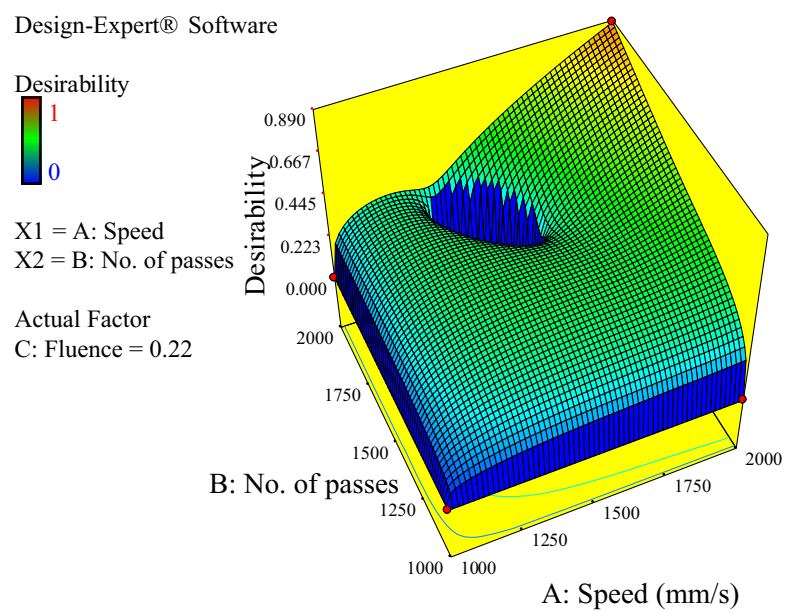

Fig. 19 Combined desirability 3D plot for laser processing of H13 tool steel, with laser scanning speed, number of passes and fluence (at $220 \mathrm{~mJ} / \mathrm{cm}^{2}$ ) as input parameters respectively 
Table 11 Validation - 'depth of cut'

\begin{tabular}{llllll}
\hline Speed $(\mathrm{mm} / \mathrm{s})$ & No. of passes & $\begin{array}{l}\text { Fluence } \\
\left(\mathrm{mJ} / \mathrm{cm}^{2}\right)\end{array}$ & $\begin{array}{l}\text { Predicted depth } \\
\text { of cut }(\mu \mathrm{m})\end{array}$ & $\begin{array}{l}\text { Validated depth } \\
\text { of cut }(\mu \mathrm{m})\end{array}$ & $\begin{array}{l}\text { Percentage } \\
\text { difference }(\%)\end{array}$ \\
\hline 2000 & 220 & 75.6 & 73 & 3.38 \\
\hline
\end{tabular}

Knowledge from the ablation profiling experiments was adapted for the statistical modelling of $\mathrm{H} 13$ ablation with regards to responses considered, fluences between 220 and $320 \mathrm{~mJ} / \mathrm{cm}^{2}$ were selected, well above the ablation threshold of $120 \mathrm{~mJ} / \mathrm{cm}^{2}$ identified in the plot.

Figure 5 demonstrates two different ablation regions. Similar phenomena were observed before during femtosecond laser ablation [12, 31-35]. A separate piece of research is currently being conducted by the authors on the fast holographic imaging to understand the ablation mechanisms.

\section{Heat affected zone characteristics}

The lower fluence regime of $220 \mathrm{~mJ} / \mathrm{cm}^{2}$ favours less HAZ generation with this picosecond laser. There was the need for a compromise between higher etch rates and HAZ generation during processing. While increased processing speed would comparatively give less HAZ on the tool steel during patterning, material removal would be reduced. The optimized RSM model translates to a more effective laser patterning process for $\mathrm{H} 13$ tool steel, with limited energy wastage, shorter processing time and recommends an easy strategy for effecting deterministic pattern depths.

\section{Groove taper}

For a Gaussian beam, as with the picosecond laser used in this investigation, taper formation is inherent to its converging-diverging beam shape. Also, due to the ultrashort pulse (10 ps) duration of the picosecond laser, a lower taper kerf is expected. Since taper formation was desirable in the formation of narrow tipped riblets on ABS plastics, the picosecond laser proved well suited to the investigation, with the fabrication on steep taper on the grooves machined on $\mathrm{H} 13$ from which the riblets were moulded.

Additionally, for a Gaussian beam, maximum energy intensity is concentrated at the centre of the beam profile. Hence there is an expected decrease in the kerf width progressively downwards from the specimen surface to its bottom end. As shown in the model perturbation plot for kerf width (Fig. 15), increase in laser scanning speed caused a decrease in the kerf width. Furthermore, increases in pulse energy enhance more material removal that leads to enlarged kerf width.

Major factors that affect taper formation are: laser fluence, scanning speed (which has direct effect on kerf width), pulse frequency, depth of cut and focus position.

The laser fluences considered in this research (under similar laser processing conditions) did not show any considerable consequence on picosecond machined grooves on $2 \mathrm{~mm}$ thick H13 plates, which agreed with data from Dubey et al. [40]. 


\section{Material removal rate}

The material removal rate $\left(M R R, \mathrm{~mm}^{3} / \mathrm{min}\right)$ can be calculated as:

$$
M R R=\frac{\text { Machine volume }\left(\mathrm{mm}^{3}\right)}{\text { Process time }(\min )}=>\frac{A \times \mathrm{L}}{n \times{ }^{\mathrm{L}} / \text { vel }}
$$

Where:

A is surface area machined $\left(\mathrm{mm}^{2}\right)$

$\mathrm{L} \quad$ is the laser machining travel length $(\mathrm{mm})$

$\mathrm{n}$ is number of laser machining passes

vel is laser machining velocity $(\mathrm{mm} / \mathrm{min})$

By substituting respective values into equation (16), the material removal rate $(M R R)$ for the model (depth of cut), as presented in Table 9, was derived. With a laser scanning length of $30 \mathrm{~mm}$ and an average kerf of $65 \mu \mathrm{m}$, a range of $M R R$ between $0.14-0.16 \mathrm{~mm}^{3} / \mathrm{min}$ was arrived at, for the respective 'Predicted' and 'Validated' values of depth of cut (processed at an average of $5.5 \mathrm{~W}$ and $205 \mathrm{kHz}$ ).

\section{Pattern transfer/replication}

There were noticeable differences with the geometries of the picosecond laser patterned structures on $\mathrm{H} 13$ (secondary tool inserts with grooves and dimples respectively) and the replicated inverse patterns (riblets and bump) on ABS as shown in Figs. 8, 10 and 11. This disparity in moulding structural fidelity can be attributable to the aspect ratios of the patterns considered, while the dimples, with an average base diameter of $131 \mu \mathrm{m}$ and top to bottom depth of $202 \mu \mathrm{m}$, achieved $85 \%$ total depths replicated on consequent bumps for ABS plastic sheets. The smoother surface observed at the tip of replicated ABS pattern in Fig. 9, could be as a result of unfilled space the bottom of the micro-groove on $\mathrm{H} 13$ tool. The microgrooves (on $\mathrm{H} 13$, with an average of $80 \mu \mathrm{m}$ kerf) to riblets on ABS transfer fidelity (average $40 \%$ ) were much lower, due to tapered geometry, which occasioned a very narrow bottom $(\leq 12 \mu \mathrm{m})$. Hence there was less volumetric filling during the injection moulding process.

\section{Conclusion}

The following conclusions can be derived from this research work:

i) Research findings demonstrated the suitability of predicting depth of cut (between 40-100 $\mu \mathrm{m}$ ) for H13 tool steel surface patterning, with $96 \%$ accuracy, for an optimal combination of input processing parameters of fluence, processing speed and number of laser scans.

ii) The energy density (fluence) of the interacting laser was considered the most dominant processing parameter in determining depth with $\mathrm{H} 13$ tool patterning, at a specified pulse frequency. The heat affected zones is likewise affected by the processing laser fluence. 
iii) The material removal rate $(M R R)$ for the depth of cut model was up to $0.16 \mathrm{~mm}^{3}$ / min, with $89 \%$ conformity between the 'Predicted' and 'Validated' values of depth of cut.

iv) There was better volumetric filling for the dimple (on H13 tool steel) to bump on ABS plates, than with the grooves to riblets, due to the narrow taper associated the less than $75 \mu \mathrm{m}$ kerf width.

v) The desirability of use of picosecond (Gaussian beam) laser for the machine of grooves on $\mathrm{H} 13$ for the injection moulding of triangularly tipped riblets on ABS plastics was demonstrated.

vi) Taper formation though desirable in this work, is difficult to control due to the complex interplay of laser fluence, scanning speed, pulse frequency, depth of cut and focus position.

Acknowledgments One of the authors acknowledges the doctoral research scholarship provided by the Federal Government of Nigeria (TETFUND) in conjunction with the Federal University of Petroleum Resources Effurun (FUPRE).

Open Access This article is distributed under the terms of the Creative Commons Attribution 4.0 International License (http://creativecommons.org/licenses/by/4.0/), which permits unrestricted use, distribution, and reproduction in any medium, provided you give appropriate credit to the original author(s) and the source, provide a link to the Creative Commons license, and indicate if changes were made.

\section{References}

1. Sommers, A.D., Jacobi, A.M.: Creating micro-scale surface topology to achieve anisotropic wettability on an aluminum surface. J. Micromech. Microeng. 16, 1571 (2006)

2. Qian, B., Shen, Z.: Fabrication of superhydrophobic surfaces by dislocation-selective chemical etching on aluminum, copper, and zinc substrates. Langmuir 21(20), 9007-9009 (2005)

3. Su, Y.-C., Shah, J., Lin, L.: Implementation and analysis of polymeric microstructure replication by micro injection molding. J. Micromech. Microeng. 14(3), 415 (2004)

4. Griffiths, C., et al.: The effects of tool surface quality in micro-injection moulding. J. Mater. Process. Technol. 189(1), 418-427 (2007)

5. Steen, W.M., Mazumder, J.: Laser material processing. Springer, Berlin (2010)

6. Mazhukin, V.I., Demin, M.M., Shapranov, A.V.: High-speed laser ablation of metal with pico- and subpicosecond pulses. Appl. Surf. Sci. 302, 6-10 (2014)

7. Guo, W., LASER MICRO/NANO SCALE SURFACE PATTERNING BY PARTICLE LENS ARRAY, in School of Materials Corrosion and Protection Centre, Faculty of Engineering and Physical Sciences. 2009, The University of Manchester: Manchester, U. K. p. 220.

8. Zawadzka, A., et al. Laser ablation and thin film deposition. in Transparent Optical Networks (ICTON), 2011 13th International Conference on. 2011: IEEE.

9. Gillner, A., Horn, A.: Ablation, in tailored light 2, pp. 343-363. Springer, Berlin (2011)

10. Raciukaitis, G. and M. Gedvilas. Processing of Polymers by UV Picosecond Lasers. in Proceedings of 24 th ICALEO Conference. 2005.

11. Lucas, L., Zhang, J.: Technology report-femtosecond laser micromachining-a back-to-basics primer on ultrafast-pulse laser processing. Ind Laser Solutions-for Manuf 27(4), 29 (2012)

12. Nolte, S., et al.: Ablation of metals by ultrashort laser pulses. JOSA B 14(10), 2716-2722 (1997)

13. Bäuerle, D.: Laser processing and chemistry. Springer, Berlin (2011)

14. Ferreira, J., Mateus, A.: Studies of rapid soft tooling with conformal cooling channels for plastic injection moulding. J. Mater. Process. Technol. 142(2), 508-516 (2003)

15. Guarise, M.: Filling of micro injection moulded parts: an experimental investigation,technical University of Denmark, DTU, DK-2800 Kgs. Lyngby, Denmark (2007) 
16. Mosaddegh, P., Angstadt, D.C.: Micron and sub-micron feature replication of amorphous polymers at elevated mold temperature without externally applied pressure. J. Micromech. Microeng. 18(3), 035036 (2008)

17. Giboz, J., Copponnex, T., Mélé, P.: Microinjection molding of thermoplastic polymers: a review. J. Micromech. Microeng. 17(6), R96 (2007)

18. Gadegaard, N., Mosler, S., Larsen, N.B.: Biomimetic polymer nanostructures by injection molding. Macromol. Mater. Eng. 288(1), 76-83 (2003)

19. Sha, B., et al.: Investigation of micro-injection moulding: factors affecting the replication quality. J. Mater. Process. Technol. 183(2), 284-296 (2007)

20. MetalSupplies, H13 Tool Steel data sheet, Metal Supplies Ltd.

21. PERRITE. Ronfalin ABS Compounds. 201310 August 2013]; Available from: http://www.perrite.com/ products-ronfalin-abs.aspx.

22. Box, G.E., Wilson, K.: On the experimental attainment of optimum conditions. J. R. Stat. Soc. Ser. B Methodol. 13(1), 1-45 (1951)

23. Myers, R.H., Montgomery, D.C., Anderson-Cook, C.M.: Response surface methodology: process and product optimization using designed experiments, vol. 705. Wiley, Hoboken (2009)

24. Kuar, A., Dhara, S., Mitra, S.: Multi-response optimisation of Nd: YAG laser micro-machining of die steel using response surface methodology. Int. J. Manuf. Technol. Manag. 21(1), 17-29 (2010)

25. Badkar, D.S., Pandey, K.S., Buvanashekaran, G.: Application of the central composite design in optimization of laser transformation hardening parameters of commercially pure titanium using Nd: YAG laser. Int. J. Adv. Manuf. Technol. 59(1-4), 169-192 (2012)

26. Elmesalamy, A., et al.: Understanding the process parameter interactions in multiple-pass ultra-narrowgap laser welding of thick-section stainless steels. Int. J. Adv. Manuf. Technol. 68(1-4), 1-17 (2013)

27. Box, G.E., Draper, N.R.: Empirical model-building and response surfaces. Wiley, Hoboken (1987)

28. Box, G.E., Draper, N.R.: Response surfaces, mixtures, and ridge analyses, vol. 649. Wiley, Hoboken (2007)

29. Meunier, M., Piquē, A., Sugioka, K.: Laser precision microfabrication, vol. 135. Springer, Berlin (2010)

30. Rodríguez-Marín, F., et al.: A correction factor for ablation algorithms assuming deviations of lambertBeer's law with a gaussian-profile beam. Appl. Phys. Lett. 100(17), 173703 (2012)

31. Dachraoui, H., Husinsky, W., Betz, G.: Ultra-short laser ablation of metals and semiconductors: evidence of ultra-fast coulomb explosion. Applied Physics A. 83(2), 333-336 (2006)

32. Dachraoui, H., Husinsky, W.: Fast electronic and thermal processes in femtosecond laser ablation of Au. Appl. Phys. Lett. 89(10), 104102 (2006)

33. Hashida, M., et al.: Ion emission from a metal surface through a multiphoton process and optical field ionization. Phys. Rev. B 81(11), 115442 (2010)

34. Tao, S., Wu, B.: The effect of emitted electrons during femtosecond laser-metal interactions: a physical explanation for coulomb explosion in metals. Appl. Surf. Sci. 298, 90-94 (2014)

35. Zelgowski, J., et al. Novel industrial laser etching technics for sensors miniaturization applied to biomedical: a comparison of simulation and experimental approach. in SPIE LASE. 2014: International Society for Optics and Photonics.

36. Russo, R.E.: Laser ablation. Appl. Spectrosc. 49(9), 14A-28A (1995)

37. Chang, J.J., Warner, B.E.: Laser-plasma interaction during visible-laser ablation of methods. Appl. Phys. Lett. 69(4), 473-475 (1996)

38. Majumdar, J.D. and I. Manna. Laser processing of materials. 2003: Indian Academy of Sciences.

39. Li, L., Sobih, M., Crouse, P.L.: Striation-free laser cutting of mild steel sheets. CIRP Ann. Manuf. Technol. 56(1), 193-196 (2007)

40. Dubey, A.K., Yadava, V.: Experimental study of Nd:YAG laser beam machining — an overview. J. Mater. Process. Technol. 195(1-3), 15-26 (2008) 